\title{
The Hurricane Harvey (2017) Texas Rainstorm: Synoptic Analysis and Sensitivity to Soil Moisture
}

\author{
THOMAS J. GALARNEAU JR. \\ Department of Hydrology and Atmospheric Sciences, The University of Arizona, Tucson, Arizona, and Cooperative Institute \\ for Mesoscale Meteorological Studies, University of Oklahoma, and NOAA/OAR National Severe Storms Laboratory, \\ Norman, Oklahoma \\ XUBIN ZENG \\ Department of Hydrology and Atmospheric Sciences, The University of Arizona, Tucson, Arizona
}

(Manuscript received 17 September 2019, in final form 14 April 2020)

\begin{abstract}
A synoptic analysis and soil moisture (SM) sensitivity experiment is conducted on the record-breaking rainstorm in Texas associated with Hurricane Harvey on 26-30 August 2017. The rainstorm occurred as the moist tropical air mass associated with Harvey was lifted along a frontogenetical near-surface coastal baroclinic zone beneath the equatorward entrance region of an upper-level jet streak. The weak steering winds in Harvey's environment, allowing Harvey to remain nearly stationary, were associated with a deformation steering flow pattern characterized by a trough to the north and flanking ridges to the west and east. This pattern has occurred with other notable tropical cyclone rainstorms along the Gulf Coast, except in Harvey's case it contributed to the collocation of deep tropical moisture and a persistent midlatitude lifting mechanism. Motivated by marked increases in SM during the rainstorm, a suite of six numerical simulations is used to test the sensitivity of the Harvey rainstorm (track, intensity, and rainfall) to varying SM. These simulations include dry, realistic, and wet SM conditions and an additional three runs with the initial SM held constant throughout the simulations. The results showed that track and prelandfall intensity were most sensitive to SM. Decreased SM resulted in the 1) development of an anticyclone in the southern plains that steered Harvey farther southwest in Texas, and 2) interruption in the intensification of Harvey in the Gulf of Mexico as dry air in the Yucatan Peninsula was entrained into Harvey's circulation, contributing to a weaker system at landfall. Implications of these findings on the evolution of tropical systems are also discussed.
\end{abstract}

\section{Introduction}

Extreme rainstorms associated with slow-moving hurricanes pose significant socioeconomic impacts, particularly in the coastal zone where increasing populations put more at risk to theses hazards (Klotzbach et al. 2018a). One such extreme rainstorm occurred in the Texas coastal plain with the landfall of Hurricane Harvey on 26 August 2017. A comprehensive documentation of Harvey's life cycle is provided by Blake and Zelinsky

\footnotetext{
Supplemental information related to this paper is available at the Journals Online website: https://doi.org/10.1175/MWR-D-190308.s1.

Corresponding author: Thomas J. Galarneau Jr., tgalarneau@ ou.edu
}

(2018). Harvey remained a weak tropical disturbance for much of its existence following its emergence from the West African coast on 12 August. After Harvey crossed the Yucatan Peninsula and entered the western Gulf of Mexico on 22 August, it moved northwestward toward the Texas coast. Beginning on 24 August, Harvey underwent a period of rapid intensification reaching category-4 intensity on the Saffir-Simpson scale (Simpson and Saffir 1974) at the time of landfall near Rockport, Texas, just after 0000 UTC 26 August. Harvey began a period of increased hurricane activity in the North Atlantic Ocean basin that lasted through September (Klotzbach et al. 2018b).

The landfall of Harvey brought with it damaging winds, tornadoes, storm surge, and freshwater flooding (Blake and Zelinsky 2018). Mesovortices and smallerscale tornado-like vortices within the eyewall of Harvey 
produced local enhancements of surface wind speed and damage (Wurman and Kosiba 2018). Numerous tornadoes occurred in conjunction with minisupercells in rainbands on the east side of Harvey (Jones et al. 2019; Brauer et al. 2020) and storm surge inundation levels approached $3 \mathrm{~m}$ above ground level (Blake and Zelinsky 2018). The most impactful hazard associated with Harvey, however, was the incredible rainstorm that occurred in the Texas coastal plain. From 26 to 30 August 2017, maximum rainfall accumulations exceeded $1300 \mathrm{~mm}$ near Port Arthur, Texas, and a large area over $1000 \mathrm{~mm}$ extended from near Houston, Texas, to Port Arthur (Fig. 1a). While Texas is no stranger to flooding rainstorms associated with landfalling tropical systems, Harvey exceeded all previous rainstorms in the historical record both in terms of maximum amount observed at a single rain gauge and total volume of water produced in the rainfall region (Blake and Zelinsky 2018). The record rains contributed to a flood of historic proportions in the Texas coastal plain.

The rainstorm was driven by the repeated development of heavy-rain-producing convective systems on the east side of Harvey for several days after landfall. These convective systems resembled the principal rainband structure ubiquitous to tropical cyclones (Houze 2010, and references therein), and included several supercells that had very high precipitation efficiency (Brauer et al. 2020). A key aspect of this rainstorm was the near stationarity of Harvey over southeast Texas for several days after landfall before reemerging over the Gulf of Mexico on 28 August. In addition to Harvey's stationarity, deep tropical moisture was in place in southeast Texas as measured by a sounding taken near the eye at landfall that measured $82.8 \mathrm{~mm}$ of total column precipitable water $(\mathrm{PW})$, which is the highest $\mathrm{PW}$ ever recorded by a radiosonde in the contiguous United States (Fernández-Cabán et al. 2019). The deep moisture and instability were collocated with a stationary front extending from near Houston northeastward along the Gulf Coast. This front was important in providing a focus for ascent in an environment of deep tropical moisture, thereby comprising key ingredients for heavy rainfall (Doswell et al. 1996). The interaction of a tropical disturbance and a midlatitude front has been documented in previous rainstorms along the Texas coast (Bosart 1984), and somewhat resembles the "frontal"-type flash flood situation presented by Maddox et al. (1979).

During the Harvey rainstorm, the soil moisture content as measured by the National Aeronautics and Space Administration (NASA) Soil Moisture Active Passive (SMAP) level 4 (L4) data (Reichle et al. 2018) markedly increased over southeast Texas. Figures $1 \mathrm{~b}$ and $1 \mathrm{c}$ shows a comparison of the SMAP-L4 0-5-cm volumetric soil moisture content at 1200 UTC 23 and 27 August 2017, with the earlier time showing the antecedent conditions and the latter in the midst of the rainstorm. Soil moisture values increased from $0.2-0.3$ to 0.4 $0.6 \mathrm{~m}^{3} \mathrm{~m}^{-3}$ in the Texas coastal plain, with the largest increases occurring near Houston, Texas. The increases in soil moisture prompt questions on its influence on the evolution of the Harvey Texas rainstorm. Previous studies have suggested that evaporation over wet soils is an important (but secondary) factor in precipitation during and after landfall of tropical systems (e.g., Trenberth et al. 2007). Liu et al. (2019) also showed that evaporation of rainfall was a secondary but nonnegligible effect contributing to $15 \%-20 \%$ of the total rainfall within $100 \mathrm{~km}$ of the center of Typhoon Utor (2013).

The modulation of intensity of tropical systems after landfall by surface fluxes of heat and moisture over the land surface has been documented in Asia (Wei and Li 2013), North America (Evans et al. 2011), and Australia (Kilroy et al. 2016). Inland intensification of tropical systems in Australia can occur in situations where rainfall ahead of the cyclone moistens the desert soils and when combined with heating by insolation result in very large surface latent heat fluxes comparable to those seen over a warm ocean (Emanuel et al. 2008). These surface latent heat fluxes over moist soils are important for maintaining enhanced moisture and reduced stability to allow for continued convection near the cyclone center (Kilroy et al. 2016). The reintensification of Tropical Storm Erin (2007) over central Oklahoma on 19 August 2007 occurred over anomalously moist soil conditions associated with a wet spring and summer over the southern Great Plains (Schumacher and Davis 2010). In a modeling sensitivity study using the Advanced Research Weather Research and Forecasting (WRFARW) system, Evans et al. (2011) found that increased soil moisture in Oklahoma led to Erin's reintensification by contributing to reduced vertical mixing and a shallower boundary layer leading to an environment with increased moisture and instability. This result is consistent with Zhang et al. (2017) who showed that forecasts of intensification using the Hurricane Weather Research and Forecasting (HWRF) Model are improved when using a planetary boundary layer (PBL) parameterization that allows for a shallower PBL with stronger lowlevel inflow and convergence. Recent efforts to study the intensity evolution of tropical systems after landfall has led to the development of the "brown ocean" concept, where rainfall produces anomalously moist soil conditions and enhanced surface latent heat fluxes (e.g., Andersen and Shepherd 2017). 
a) Harvey track and NCEP Stage-IV rainfall

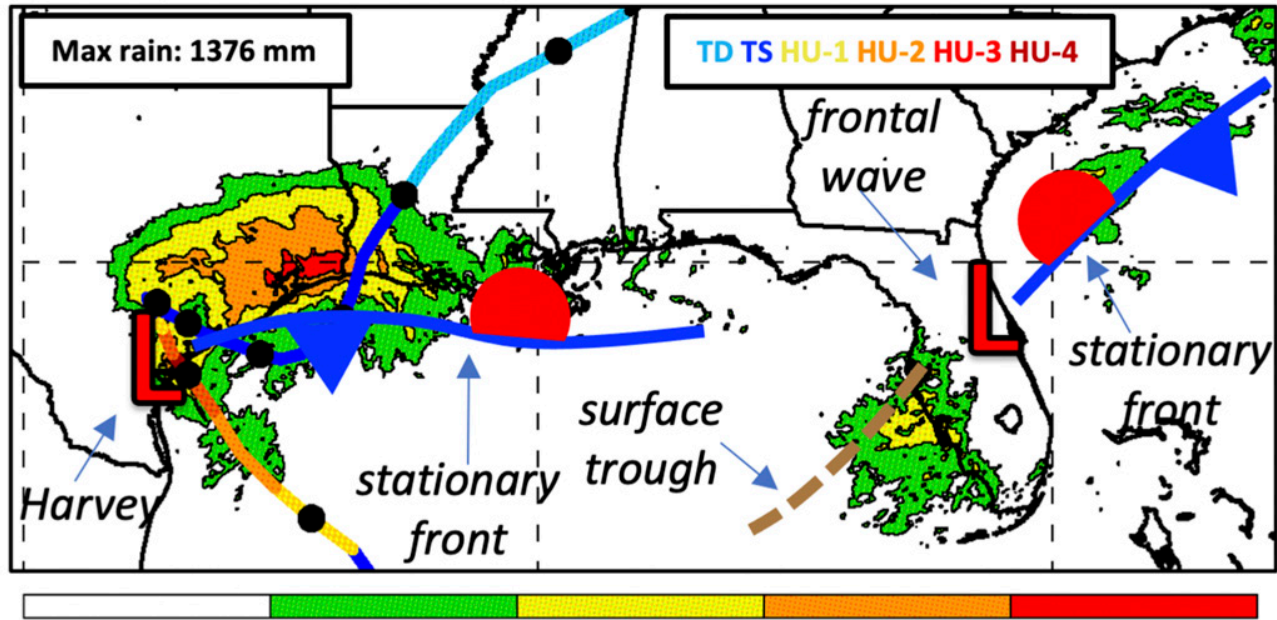

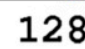

b) 1200 UTC 23 Aug 2017

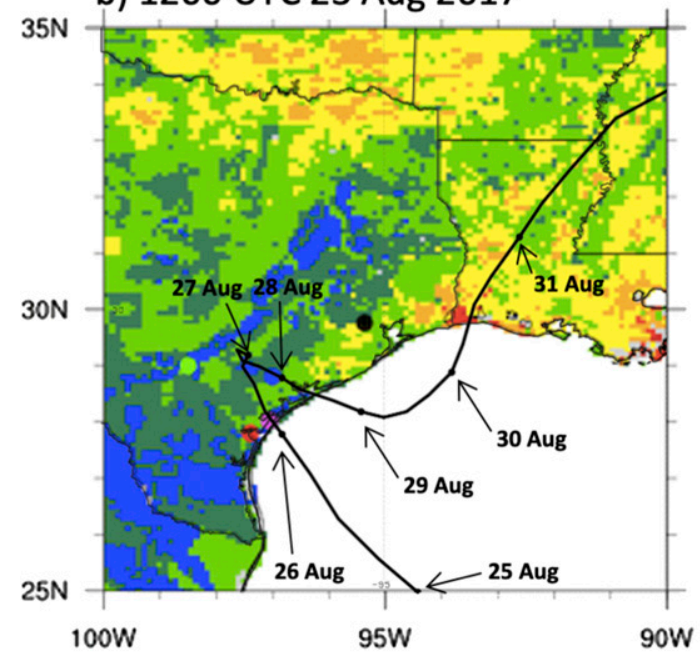

512

\section{0}

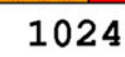

$\mathrm{mm}$
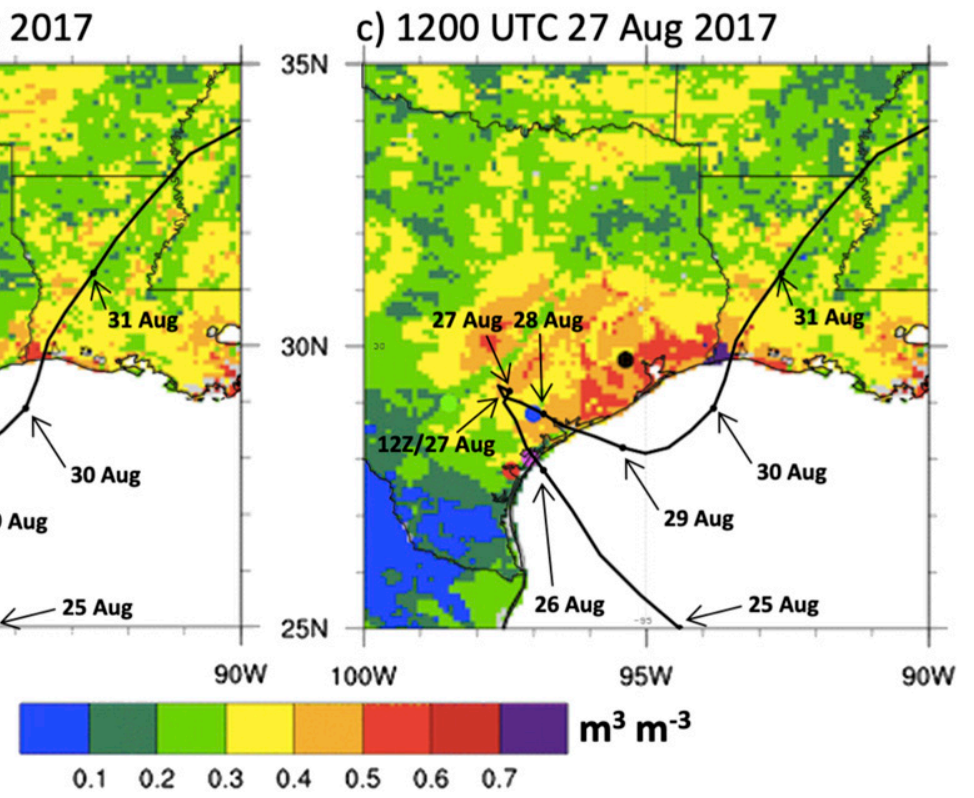

FIG. 1. (a) Stage-IV total accumulated precipitation (shaded according to the color bar; mm) for 1200 UTC 23-30 Aug. The maximum accumulated rainfall for the period is shown in the upper left. HURDAT2 track and intensity for Hurricane Harvey are shown with 0000 UTC positions marked by a black-filled circle and track color based on Saffir-Simpson scale classification according to the key. Positions of Harvey and a second low pressure center are marked by a red-filled "L" symbol, stationary surface fronts are shown by a blue line segment with conventional frontal symbols, and a surface pressure trough is indicated with a brown-dashed line segment at approximately 0000 UTC 28 Aug. The schematic surface features are based on the NOAA Ocean Prediction Center Unified Surface Analysis. Also shown is NASA 9-km L4SMAP near-surface 0-5-cm volumetric soil moisture content (shaded according to the color bar; $\mathrm{m}^{3} \mathrm{~m}^{-3}$ ) at $1200 \mathrm{UTC}$ (b) 23 and (c) 27 Aug 2017 overlaid with the HURDAT2based storm track for Harvey (black line with black-filled circles at 0000 UTC). The locations in Texas of Houston (black), Victoria (blue), Rockport (magenta), Corpus Christi (red), and just southeast of San Antonio (green) are marked by filled circles.

Clearly, the underlying soil moisture condition has the potential to impact the rainfall and intensity of tropical systems during and after landfall. Given how Harvey produced a historic rainstorm and flood and maintained tropical storm intensity for 2 days after landfall before reemerging over the Gulf of Mexico, this study aims to address the following science questions: 1) What synopticscale circulation features and physical mechanisms led to 
the extreme rains? 2) What factors set Harvey apart from previous extreme rainstorms associated with tropical systems? 3) Was the evolution of the Harvey rainstorm sensitive to the underlying soil moisture condition? Observations, operational model analysis and retrospective reanalysis fields, and a suite of convection-allowing WRF-ARW simulations will be used to answer these questions.

The remainder of the paper is organized as follows. Section 2 provides the synoptic analysis. Section 3 presents a comparison of Harvey to previous slowmoving tropical cyclones in 1979-2018. Section 4 presents the WRF-ARW model configuration and an overview of the control simulation. Section 5 presents the experimental design and results from the WRF-ARW soil moisture sensitivity experiment, and section 6 provides the concluding remarks.

\section{Synoptic analysis}

\section{a. Data and computation of steering layer flow and Petterssen frontogenesis}

The National Centers for Environmental Prediction (NCEP) Global Forecast System (GFS) analysis pressurelevel data, available at 6 -h intervals at $0.25^{\circ} \times 0.25^{\circ}$ latitude-longitude grid spacing, was used to determine the synoptic-scale environment and physical mechanisms that produced the Harvey rainstorm. Accumulated rainfall analyses in the southern Great Plains and southeast United States were derived from the NCEP Stage-IV rainfall dataset available at 4-km horizontal grid spacing (Lin 2011). The position of surface frontal zones was determined by manual analysis of surface observations and surface analyses provided by the National Oceanic and Atmospheric Administration (NOAA)/National Weather Service (NWS)/Ocean Prediction Center (OPC) unified surface analysis. Observed radar reflectivity were obtained from the Multi-Radar Multi-Sensor (MRMS) gridded composite reflectivity dataset (Lakshmanan et al. 2007; Smith et al. 2016). Observed positions of Harvey were derived from the Hurricane Best Track Database (HURDAT2; Landsea and Franklin 2013).

Potential temperature and wind on the dynamic tropopause (DT) are examined in Fig. 2 (discussed further in section $2 \mathrm{~b}$ ), which is defined as the 2.0 potential vorticity unit (PVU) surface where 1.0 PVU $=1.0 \times 10^{-6} \mathrm{~K} \mathrm{~kg}^{-1} \mathrm{~m}^{2} \mathrm{~s}^{-1}$. The computation of Harvey's steering layer flow follows the vorticity inversion method presented by Galarneau and Davis (2013, their section 2b). First, the environment wind is computed every $6 \mathrm{~h}$ at $50-\mathrm{hPa}$ increments in the 850-200-hPa layer by removing the vorticity and divergence associated with Harvey out to a given radius from the center. Then, the steering flow is defined as the spatially averaged environment wind over depths ranging from the 850-800- to 850-200-hPa layers and horizontal regions of $1^{\circ}-8^{\circ}$ radii that best matches the motion of Harvey based on positions in the HURDAT2 at $\pm 12 \mathrm{~h}$. Harvey's time-averaged best-match steering layer for 1200 UTC 24-29 August 2017 is defined as the $850-300-\mathrm{hPa}$ layer with a radius of $3^{\circ}$ for the steering analysis presented in section $2 b$.

The Petterssen frontogenesis function was used to investigate the physical mechanisms that were driving the heavy rains in southeast Texas. This form of frontogenesis relates the Lagrangian time rate of change of the potential temperature gradient to kinematic properties of the wind field, and is defined using the formulation in Keyser et al. (1988, their Eq. 1.1) as

$$
\frac{d}{d t}|\nabla \theta|=-\frac{1}{2}|\nabla \theta|(D-E \cos 2 \beta),
$$

where $d / d t=(\partial / \partial t)+u(\partial / \partial x)+v(\partial / \partial y), \nabla$ is the gradient operator on a horizontal surface, $D$ is the divergence, and $E$ is the resultant deformation. The angle $\beta$ represents the difference between the angles representing the local orientation of the isentropes and the axis of dilatation, as illustrated in Fig. 1 of Keyser et al. (1988).

\section{b. Synoptic-scale flow evolution}

As Harvey approached the southeast Texas coastline at 1200 UTC 25 August, a well-defined upper-level anticyclone (relatively higher potential temperature on the DT) was centered over Harvey and covered much of the Gulf of Mexico and stretched from the southern Great Plains to the southeastern United States (Fig. 2a). A weak upper-level cyclonic circulation was positioned west of Harvey in northern Mexico. The midlatitude westerly jet stream was positioned farther north over the northern United States, with troughs located over Montana and the northeast United States. Surface cyclogenesis was underway in central Florida on the eastern flank of Harvey's outflow anticyclone. By 0000 UTC 27 August, Harvey was located in southeast Texas (Fig. 2b). The upper-level trough over Montana had moved eastward to eastern North Dakota and extended southeastward to Missouri (Fig. 2b). The southern end of this trough was located just north of Harvey's outflow anticyclone, resulting in a marked increase in the potential temperature gradient on the DT and the development of an upper-level jet streak extending from Oklahoma and Kansas to the Appalachians. Harvey was positioned in the equatorward entrance region of this upper-level jet streak.

Harvey remained in the equatorward entrance region of an upper-level jet streak on 1200 UTC 28 August as 

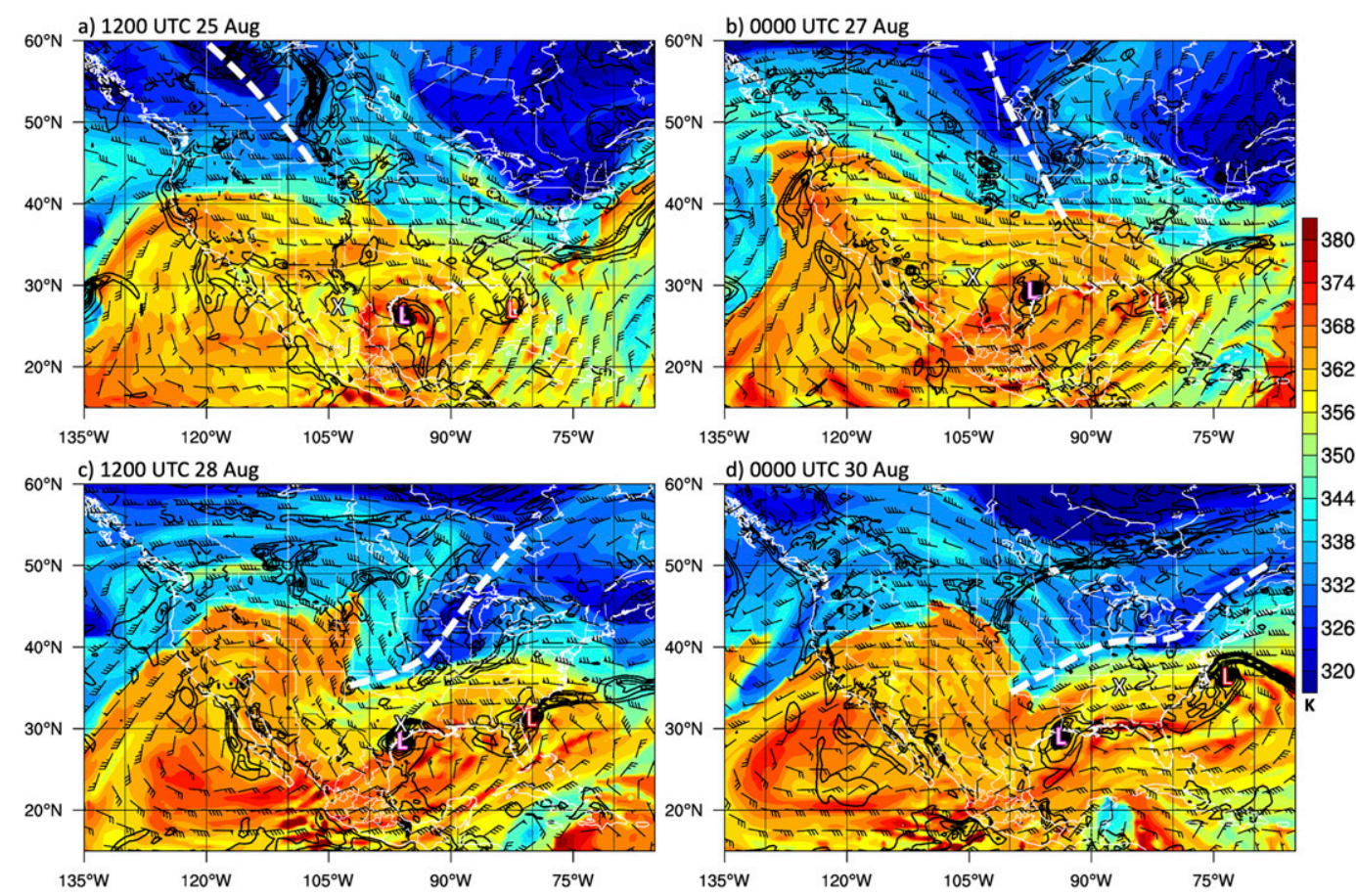

FIG. 2. The DT potential temperature (shaded according to the color bar; K), wind (half barb $=2.5 \mathrm{~m} \mathrm{~s}^{-1}$, full barb $=5.0 \mathrm{~m} \mathrm{~s}^{-1}$; and pennant $=25.0 \mathrm{~m} \mathrm{~s}^{-1}$ ), and 925-850-hPa layer-mean relative vorticity (black contours every $4.0 \times 10^{-5} \mathrm{~s}^{-1}$ starting at $4.0 \times 10^{-5} \mathrm{~s}^{-1}$ ) at (a) $1200 \mathrm{UTC} 25$, (b) 0000 UTC 27, (c) 1200 UTC 28, and (d) 0000 UTC 30 Aug 2017. Harvey and the developing extratropical cyclone in Florida are marked by the white-filled magenta "L." The upper-level midlatitude trough is marked by the white-dashed line segment, and a weak upper-level cyclonic circulation is marked by the white-filled black "X."

the midlatitude trough developed a positive tilt in response to ridge building in the western United States (Fig. 2c). Harvey and the weak upper-level cyclonic circulation in northern Mexico moved northeastward on the southeast flank of the upper-level trough through 0000 UTC 30 August, with Harvey reemerging in the Gulf of Mexico and making a second landfall on the Louisiana coastline on 30 August (Fig. 2d). The weak surface cyclone initially in Florida also moved northeastward and intensified into a mature extratropical cyclone.

A key factor contributing to the exceptional rains was the slow forward motion of Harvey after landfall. The steering layer $(850-300 \mathrm{hPa})$ averaged relative vorticity and environment wind are presented in Fig. 3. Key circulation features are labeled, with thick arrows representing streamlines of the environment wind near Harvey and deep-layer anticyclonic and cyclonic circulation features labeled "A" and "C," respectively. At 1200 UTC 25 August, Harvey was embedded in southeasterly steering flow associated with the anticyclone in the Gulf of Mexico (Fig. 3a). By 0000 UTC 27 August, as the midlatitude trough moved eastward on the north side of Harvey and the deep anticyclone remained positioned on the east side of Harvey, the configuration of the flow placed Harvey in a weak flow region (i.e., saddle point) along the axis of dilatation of a deformation flow pattern in southeast Texas (Fig. 3b). As the anticyclone developed in the western United States and the midlatitude trough moved eastward, the deformation flow pattern shifted slightly southwestward, placing Harvey in a westerly steering flow (Fig. 3c). At 0000 UTC 30 August, Harvey continued moving northeastward in the confluent southwesterly steering flow south of the trough and north of the outflow anticyclone (Fig. 3d).

\section{c. Physical mechanisms driving heavy rainfall}

The Harvey rainstorm involved the overlap of deep, tropical moisture with a persistent lifting mechanism. At 0000 UTC 23 August, Harvey and its plume of deep tropical moisture was located just west of the Yucatan in the southern Gulf of Mexico (Fig. 4a). A remnant stationary front and zonally oriented plume of enhanced PW was positioned along the Gulf Coast and a cold front extended from an extratropical cyclone in eastern Canada southwestward to the southern plains. The cold front moved southward to the Gulf Coast as surface high pressure moved to the central Great Plains through 0000 UTC 

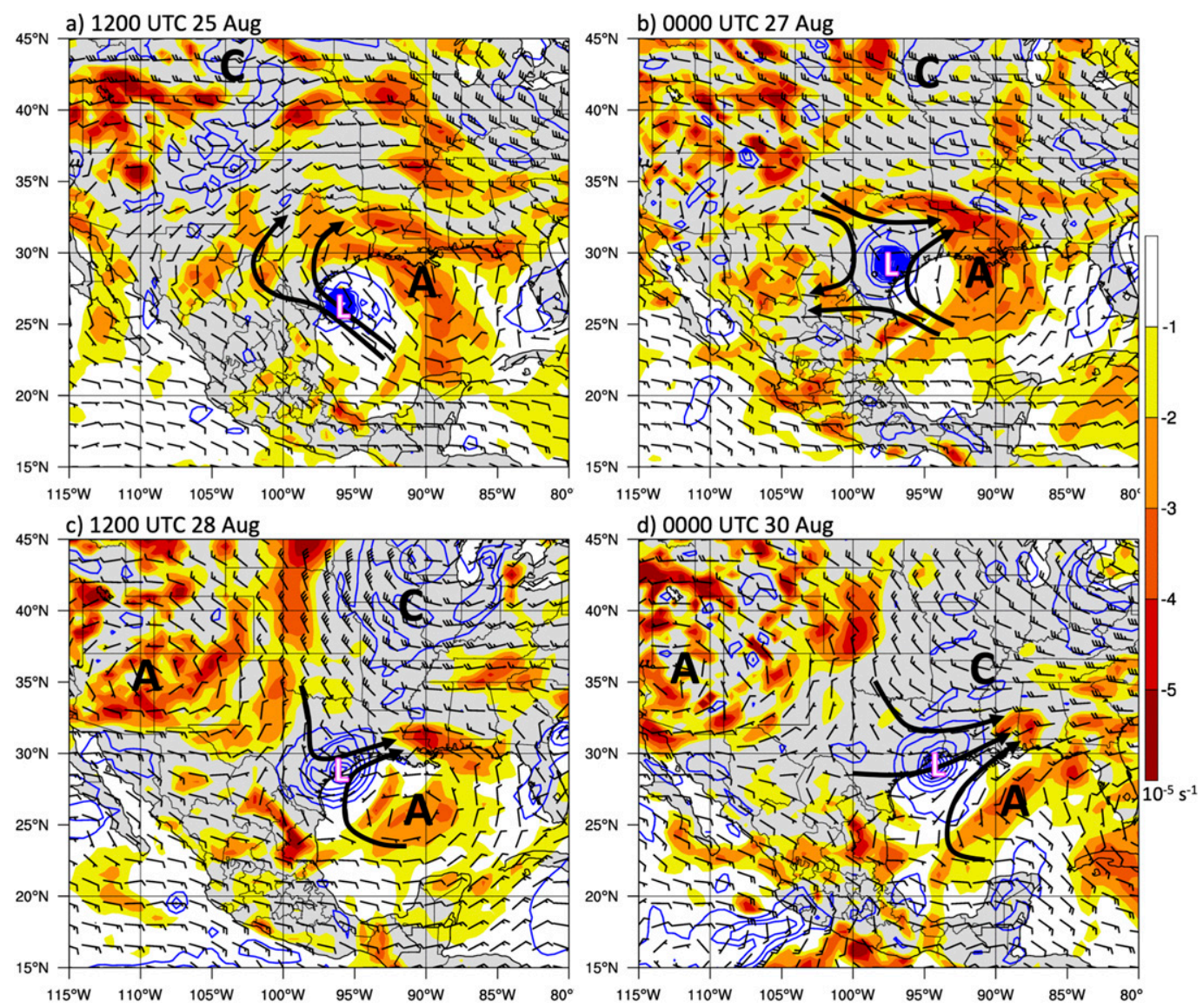

FIG. 3. 850-300-hPa steering-layer-mean environment wind (barbs as in Fig. 2) and relative vorticity (anticyclonic shaded according to the colorbar; $10^{-5} \mathrm{~s}^{-1}$; cyclonic contoured every $4.0 \times 10^{-5} \mathrm{~s}^{-1}$ starting at $2.0 \times 10^{-5} \mathrm{~s}^{-1}$ ) at (a) 1200 UTC 25, (b) 0000 UTC 27, (c) 1200 UTC 28, and (d) 0000 UTC 30 Aug 2017. The position of Harvey is labeled by a white-filled magenta "L" and anticyclonic and cyclonic circulation features are labeled "A" and "C," respectively. Approximate streamlines are marked by thick black arrows.

25 August (Figs. 4b,c). Surface low pressure formed along the cold front in Florida and Harvey's circulation began to interact with the southwest end of the cold front near the Texas coastline. By 1200 UTC 25 August, Harvey's cyclonic circulation was advecting a region of deep tropical moisture northwestward to the cold front region (Fig. 4d). Figure S1 in the online supplemental material shows a manual analysis of surface temperature and dewpoint at 1200 UTC 25 August, illustrating the presence of the welldefined stationary front (previously the cold front over the central Great Plains 2 days earlier) along the Texas coastline. This front separated the warm, moist southeasterly flow on the northeast side of Harvey from cooler, moist northeasterly flow in Texas, Louisiana, and Mississippi. After Harvey made landfall in southeast Texas, southeasterly flow on the east side of Harvey continued to facilitate the lifting of deep tropical moisture along the surface coastal front (Fig. S2 in the online supplemental material).
Close inspection of the radar reflectivity at key observation times reveals that heavy rains began along the Texas coast nearly $12 \mathrm{~h}$ prior to landfall as Harvey's moist tropical air mass was lifted in conjunction with an axis of frontogenesis aligned with the coastal front along the Texas coast (Fig. 5a). Frontogenesis persisted through 28 August (Figs. 5b-d). Intense bands of thunderstorms, resembling a principal rainband as described by Houze (2010, his Fig. 36), formed in the Gulf of Mexico east of Harvey and south of the frontogenetical coastal front. A larger area of intense rainfall overspread the region over and north of the axis of frontogenesis where the principal rainbands intersected the coastal front. The heaviest rains (>1000 mm during 1200 UTC 23-30 August 2017) occurred from Houston to Port Arthur, Texas, located on the north side of the front (Fig. 1a). The near stationarity of Harvey to the west of Houston through 28 August allowed an extended period in which Harvey's deep tropical moisture overlapped with enhanced ascent associated 


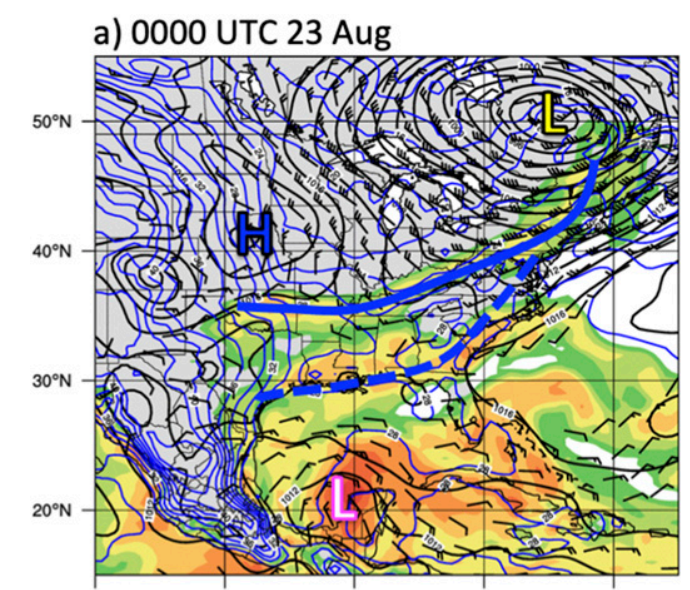

\section{b) 0000 UTC 24 Aug}
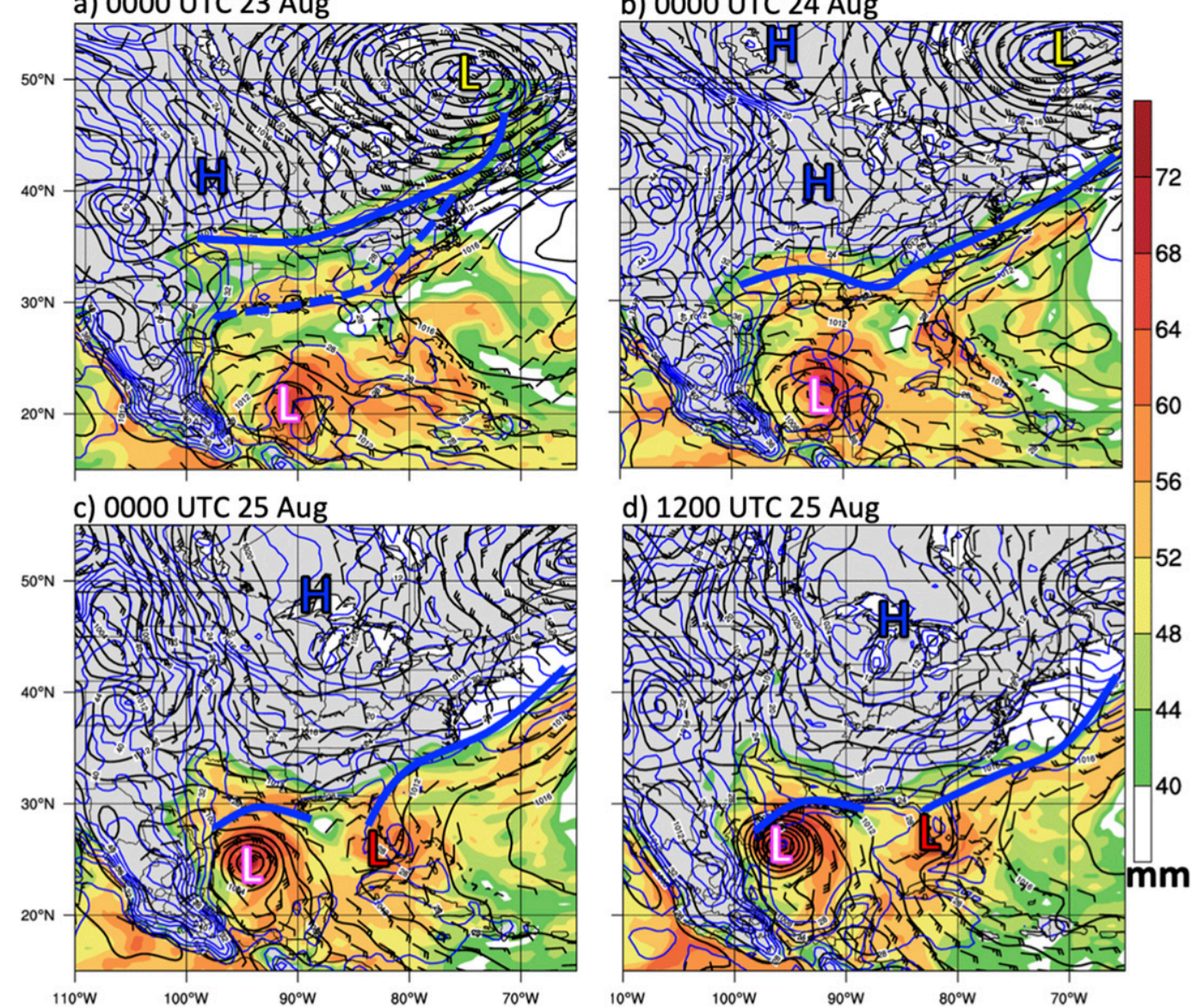
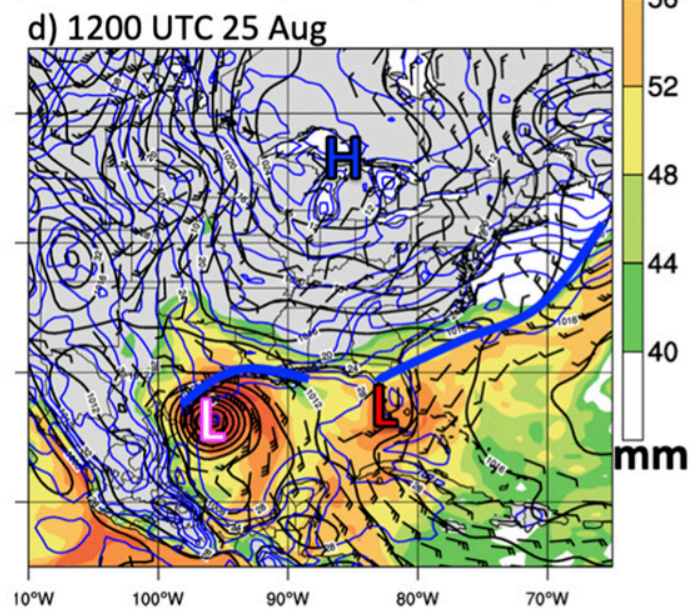

FIG. 4. Total column PW (shaded according to the colorbar; $\mathrm{mm}$ ), sea level pressure (black contours every $2 \mathrm{hPa}$ ), 2-m potential temperature (blue contours every $2^{\circ} \mathrm{C}$ ), and $850-\mathrm{hPa}$ wind (barbs as in Fig. 2) at (a) 0000 UTC 23, (b) 0000 UTC 24, (c) 0000 UTC 25, and (d) 1200 UTC 25 Aug 2017. The position of Harvey is labeled by a whitefilled magenta " $\mathrm{L}$," the surface cyclone in Florida is marked by a red-filled black " $\mathrm{L}$," the extratropical cyclone in eastern Canada is marked by a yellow-filled black " $L$," and surface high pressure centers are marked by a blue-filled black "H."' The positions of surface fronts are marked by solid blue line segments and are derived from the NOAA Ocean Prediction Center Unified Surface Analysis.

with a frontogenetical midlatitude surface front and the equatorward entrance region of the upper-level jet streak. The rains then continued in this region on 29-30 August on the northwest side of Harvey as it reemerged in the Gulf of Mexico and moved northeastward to Louisiana.

\section{Historical comparison}

\section{a. Data and methods}

To provide historical context to the Harvey rainstorm, the forward motion and rainfall associated with all North Atlantic tropical cyclones that made landfall in the contiguous United States in 1979-2018 are examined. For each system, the 6 hourly forward motion is determined based on their positions in the HURDAT2 at $\pm 12 \mathrm{~h}$. Then, the average magnitude of the forward motion vector is taken for the period from 1 day prior to landfall to 3 days after landfall (defined as day -1 , day 0 , day +1 , day +2 , and day +3 ). In the same period, the total accumulated rainfall within $500 \mathrm{~km}$ of the landfall point is computed using the NOAA Climate Prediction Center Unified Precipitation Dataset (UPD; Higgins et al. 2000) available daily at $0.25^{\circ}$ latitude-longitude grid spacing. The UPD-derived accumulated rainfall for Harvey in this period is shown in Fig. S3 in the online supplemental material. The gridpoint maximum accumulated rainfall is used in the climatological analysis rather than area-mean or volumetric rainfall because the rain gauge-based UPD dataset does not contain information over nearby oceanic regions. Therefore, for instance, the area-mean calculation for a tropical system that made landfall in Florida would have a relatively 

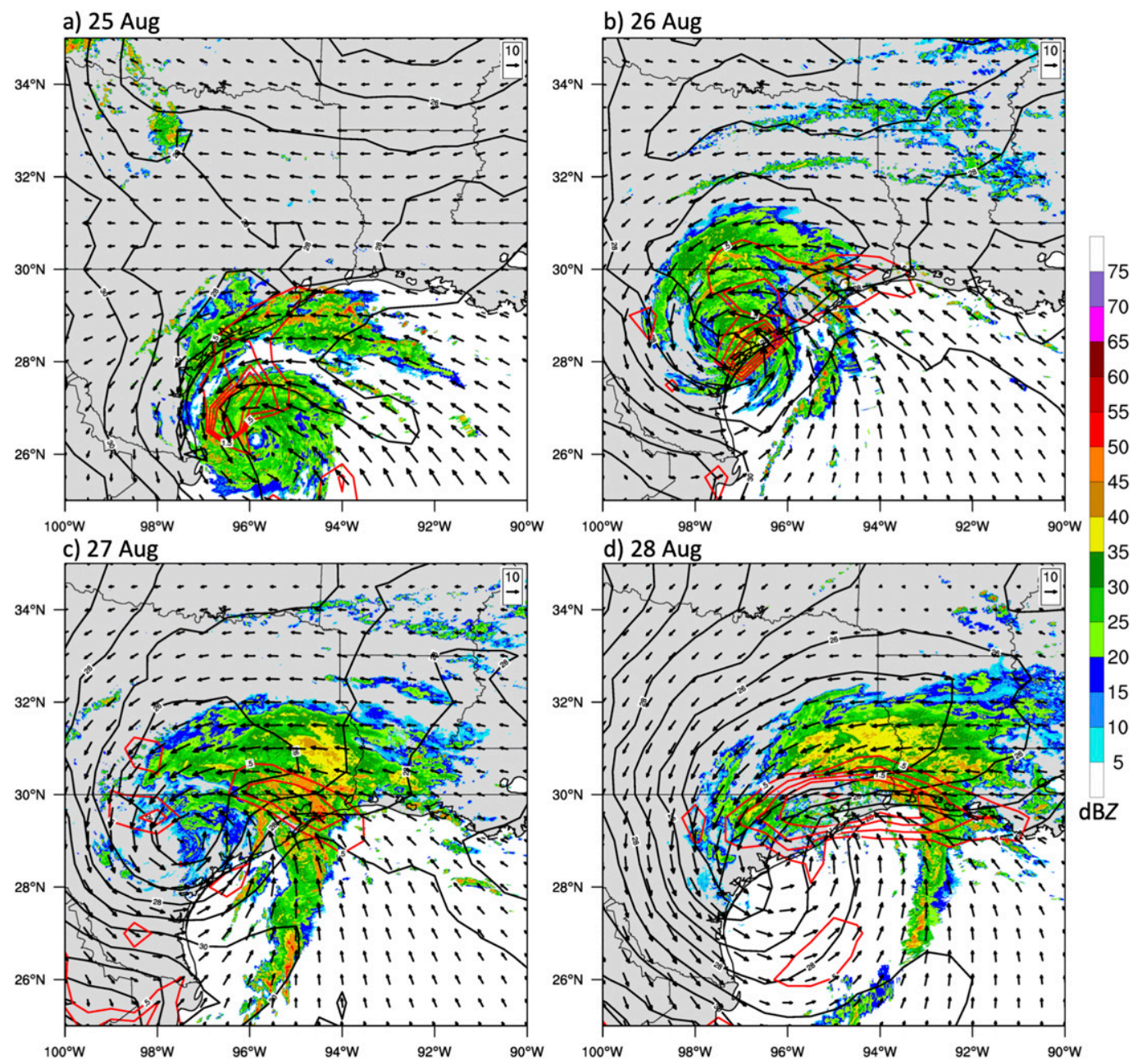

FIG. 5. MRMS reflectivity (shaded; dBZ) at 1200 UTC and daily mean 1000-900-hPa layer-mean wind (arrows; $\mathrm{m} \mathrm{s}^{-1}$ ), potential temperature (solid black contours every $1^{\circ} \mathrm{C}$ ), and Petterssen frontogenesis [solid red contours at $0.5,1,1.5,2,4,7,10,20,40$, and $\left.80^{\circ} \mathrm{C}(100 \mathrm{~km})^{-1}(3 \mathrm{~h})^{-1}\right]$ on (a) 25, (b) 26, (c) 27, and (d) 28 Aug 2017.

limited number of land grid points compared to a system that made landfall in southeast Texas. So, the area-mean or volumetric calculation may not best represent the amount of rainfall that occurred within $500 \mathrm{~km}$ of the landfall point.

Analysis of synoptic-scale circulation features and characterization of the environment moisture and ascent forcing is derived from the NCEP Climate Forecast System Reanalysis (CFSR) (Saha et al. 2010, 2014) pressure-level data available four times daily at $0.5^{\circ} \times 0.5^{\circ}$ horizontal grid spacing. The available atmospheric water vapor is computed as the daily and area-mean total column PW in a $2^{\circ} \times 2^{\circ}$ region centered on the location of the maximum accumulated rainfall from day -1 through day +3 . The ascent forcing at $700 \mathrm{hPa}$ is computed as a daily and areamean in the same region, and is computed as the righthand side of the quasigeostrophic omega equation which is defined as [Bluestein 1992, his Eq. (5.7.54)]:

$$
\left(\nabla_{p}^{2}+\frac{f_{0}^{2}}{\sigma} \frac{\partial^{2}}{\partial p^{2}}\right) \omega=-2 p \cdot \mathbf{Q}
$$

where $\omega$ is the vertical velocity, $\nabla_{p}$ is the gradient operator on a pressure surface, $\nabla_{p}^{2}$ is the Laplacian operator on a pressure surface, $p$ is pressure, $\sigma$ is static stability, $f_{0}$ is the Coriolis constant $\left(10^{-4} \mathrm{~s}^{-1}\right)$, and

$$
\mathbf{Q}=-\frac{R_{d}}{\sigma p}\left(\begin{array}{l}
\frac{\partial \mathbf{V}_{g}}{\partial x} \cdot \nabla_{p} T \\
\frac{\partial \mathbf{V}_{g}}{\partial y} \cdot \nabla_{p} T
\end{array}\right)=\left(\begin{array}{c}
Q_{1} \\
Q_{2}
\end{array}\right) .
$$

In the definition of $\mathbf{Q}, R_{d}$ is the gas constant for dry air, $\mathbf{V}_{g}$ is the geostrophic wind, $T$ is the temperature, $Q_{1}$ and $Q_{2}$ are the zonal and meridional components of $\mathbf{Q}$, and all other symbols are the same as defined for Eq. (2). 
Positive and negative contributions from the right-hand side of Eq. (2) indicate quasigeostrophic forcing for ascent and descent, respectively. As an illustrative example, the 700-hPa ascent forcing for Harvey at 1200 UTC 27 August 2017 is shown in Fig. S4 in the online supplemental material. A region of ascent forcing $\left(-2 \nabla_{p} \cdot \mathbf{Q}>0\right)$ was located in the eastern flank of Harvey in the heavy rainfall region. In the $2^{\circ} \times 2^{\circ}$ region centered on the location of the maximum accumulated rainfall, $\mathbf{Q}$ was oriented across the isotherms pointing toward warmer air which indicates frontogenesis (Keyser et al. 1988) and shows that the nearsurface frontogenesis along the coastal front shown in Fig. 5 extends upward through $700 \mathrm{hPa}$.

\section{b. Climatology}

In 1979-2018, 172 tropical cyclones made landfall ${ }^{1}$ in the contiguous United States. The distribution of mean tropical cyclone motion from day -1 through day +3 is shown in Fig. 6a. In the positively skewed distribution, most landfalling tropical cyclones have mean forward motion of $5-7 \mathrm{~m} \mathrm{~s}^{-1}$. The subset of 22 slowest-moving tropical cyclones with motion $<3 \mathrm{~m} \mathrm{~s}^{-1}$ (and to a lesser extent the subset of 40 tropical cyclones moving 3$5 \mathrm{~m} \mathrm{~s}^{-1}$ ) produce significantly more maximum rainfall than faster moving systems. The scatterplot of mean motion versus maximum accumulated rainfall shows that both fast and slow moving systems can produce significant rainstorms with maximum rainfall $100-300 \mathrm{~mm}$ (Fig. 6b). However, all rainstorms with accumulations over $400 \mathrm{~mm}$ occurred with slow-moving systems $\left(<5 \mathrm{~m} \mathrm{~s}^{-1}\right)$ with exception of Floyd (1999) which underwent extratropical transition (Atallah and Bosart 2003). The Harvey rainstorm was the most significant rainstorm in the climatology, producing maximum rainfall nearly $50 \%$ larger than the second and third ranked rainstorms associated with Georges (1998) and Florence (2018).

The maximum rainfall-relative tropical cyclone tracks for the top six rainfall events ${ }^{2}$ is shown in Fig. 7a. Florence and Danny had somewhat straight, slow motion as they passed near the maximum rainfall location. Harvey, Georges, Alberto, and Allison had slow forward motion that was accompanied by an abrupt change in direction, with Harvey and Allison having the longest duration of being located within $4^{\circ}$ of the maximum rainfall location. The steering flow analysis shows that Allison's slow motion and change in direction occurred as it became

\footnotetext{
${ }^{1} \mathrm{~A}$ landfall event is defined in this study as the time at which the grid point in the CFSR nearest to the HURDAT2 storm center is flagged as a land surface in the continental United States.

2 1) Harvey (2017), 2) Georges (1998), 3) Florence (2018), 4) Danny (1997), 5) Alberto (1994), and 6) Allison (2001).
}
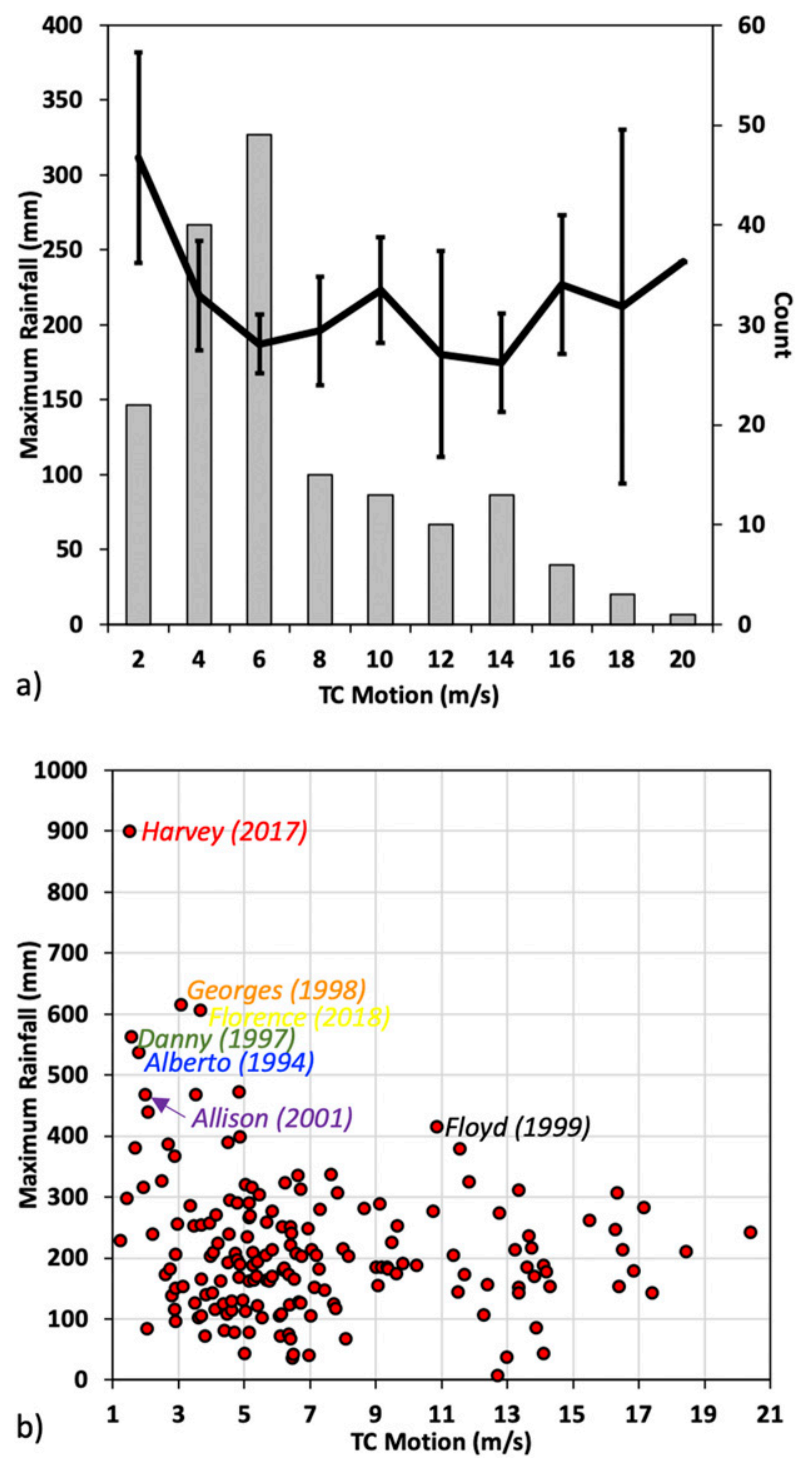

FIG. 6. (a) Histogram of mean tropical cyclone forward motion $\left(\mathrm{m} \mathrm{s}^{-1}\right)$ from day -1 through day +3 (gray bars) and mean maximum accumulated rainfall ( $\mathrm{mm}$; black line) as a function of forward motion for the same period within $500 \mathrm{~km}$ of the tropical cyclone landfall location. Error bars represent the $90 \%$ confidence interval. (b) Scatterplot of mean tropical cyclone motion $\left(\mathrm{m} \mathrm{s}^{-1} ; x\right.$ axis) vs maximum accumulated rainfall ( $\mathrm{mm} ; y$ axis) from day-1 through day +3 . Selected tropical cyclones are labeled. The figure is based on all 172 tropical cyclones that made landfall in the continental United States during 1979-2018.

embedded in a deformation flow pattern with flanking troughs to the south and north and ridges to the west and east, much like for Harvey (not shown). The time series box and whisker plots of daily rainfall for all slow-moving tropical systems (defined herein as motion $<5 \mathrm{~m} \mathrm{~s}^{-1}$ ) shows that on average the rains occur on day 0 through day +2 with the heaviest rains occurring on day +1 after landfall (Fig. 7b). The top six events show a similar pattern 
a) TC tracks in rain-max-relative coordinates

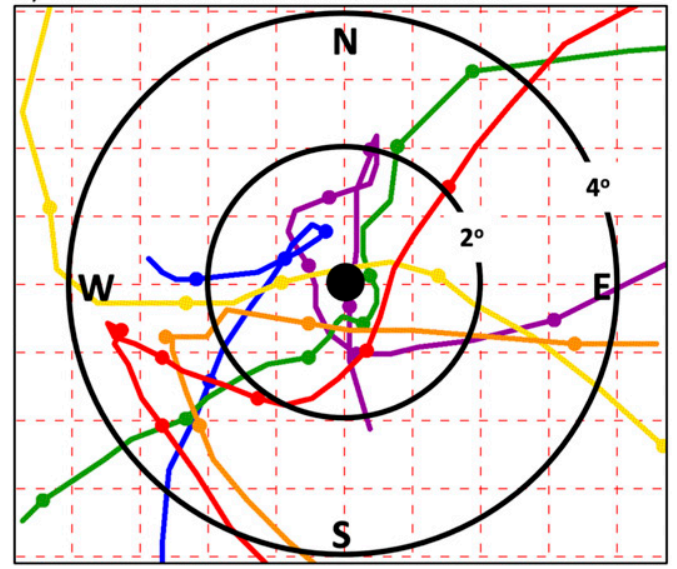

c) Precipitable water

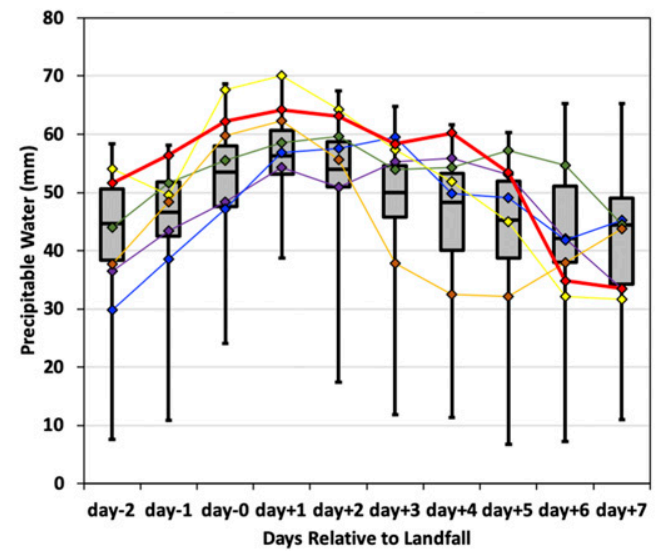

b) Daily rainfall

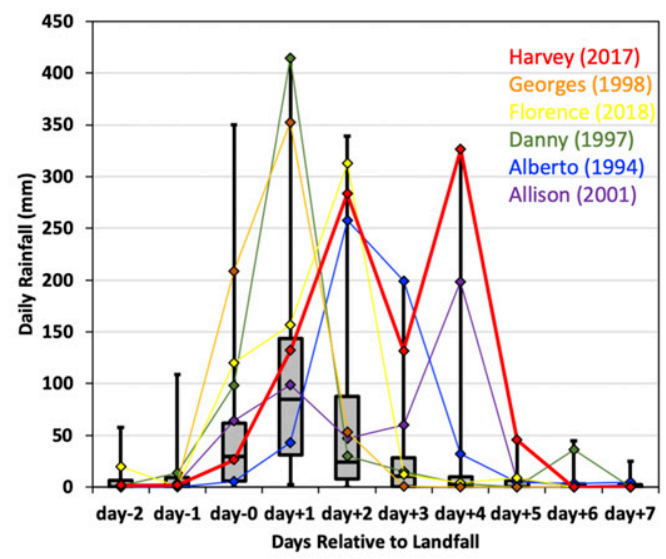

d) QG ascent forcing $(-2 \boldsymbol{\nabla} \cdot \boldsymbol{Q})$ at $700 \mathrm{hPa}$

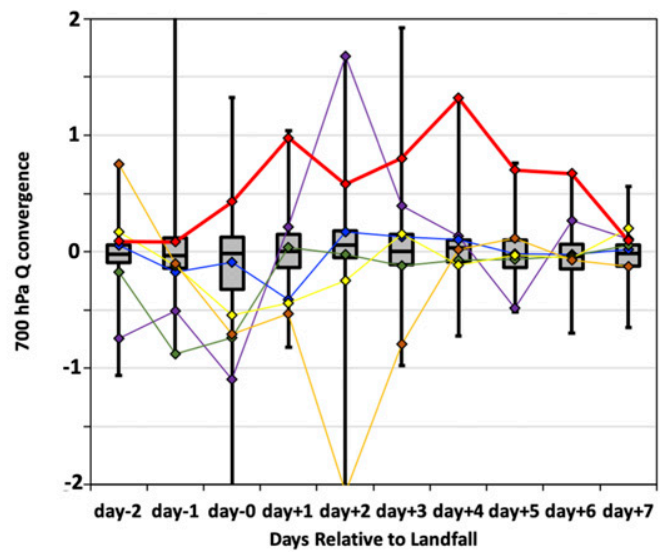

FIG. 7. (a) Tropical cyclone tracks in maximum rainfall location-relative coordinates (each red box is $1^{\circ} \times$ $1^{\circ}$ latitude-longitude) (range rings in black mark distance from maximum rainfall location; ${ }^{\circ}$ ) for Harvey (2017; red), Georges (1998; orange), Florence (2018; yellow), Danny (1997; green), Alberto (1994; blue), and Allison (2001; purple). Locations at 0000 UTC are marked by the filled circles. Also shown are box-and-whisker plots of (b) daily maximum rainfall $(\mathrm{mm})$, (c) area-mean $\mathrm{PW}(\mathrm{mm})$, and (d) area-mean $700-\mathrm{hPa}-2 \nabla \cdot \mathbf{Q}\left(\times 10^{-12} \mathrm{~Pa} \mathrm{~m}^{-2} \mathrm{~s}^{-1}\right)$ from day -2 through day +7 at the maximum rainfall location as defined in Fig. $6 \mathrm{~b}$ for the 62 slow-moving (mean motion $<5 \mathrm{~m} \mathrm{~s}^{-1}$ from day -1 through day +3 ) landfalling systems in 1979-2018. The area-mean PW and $-2 \nabla \cdot \mathbf{Q}$ are taken as the $2^{\circ} \times 2^{\circ}$ region centered on the maximum rainfall location. The whiskers mark the maximum and minimum values; the top and bottom of the box mark the 75th and 25th percentile, respectively; and the middle of the box marks the median value. Values for individual storms are colored according to the convention in (a).

with the heaviest rains occurring within the day $0-$ day +2 time window. The Harvey and Allison rainstorms have two relative peaks in daily rainfall, with the second peak occurring at day +4 , suggesting that these rainstorms occurred over a longer duration than other rainstorms.

The time series of PW shows a peak on average at day +1 , much like for rainfall (Fig. 7c). The relative peak in $\mathrm{PW}$ at day +1 is also seen in the top six events, except for Alberto and Allison which peak at day +3 and day +4 . Noteworthy is the extended period of time (from day -2 through day +5 ) in which Harvey's PW remained above the 75th percentile of all slow-moving tropical cyclone rainstorms. The time series of ascent forcing is more complex but shows a maximum at day +2 in the climatology (Fig. 7d). Harvey and Allison have ascent forcing in the environment during their respective rainstorms, whereas the other top events have neutral to negative ascent forcing. This result shows that quasigeostrophic ascent forcing (a proxy for environment baroclinicity) is not a necessary condition for a significant rainstorm associated with a slow-moving tropical cyclone. This result makes sense since the climatology is for slow-moving systems which are embedded in weak flow regimes with weak background baroclinicity. In the case of Harvey, however, it is the overlap of deep tropical moisture and midlatitude quasigeostrophic forcing for ascent (i.e., baroclinicity) that may have turned a significant rainstorm into a historic rainstorm. 
Table S1 in the online supplemental material summarizes the rainfall and environment moisture and quasigeostrophic ascent forcing for all 62 slow-moving tropical systems. Harvey recorded six days in which PW was greater than the 75th percentile of the slow-moving tropical cyclone climatology and there was quasigeostrophic forcing for ascent. No other storm in the climatology met this condition for more than 3 days. It is argued that the extended period in which deep tropical moisture overlapped with quasigeostrophic forcing for ascent is what set Harvey apart from other rainstorms in 1979-2018.

\section{Numerical simulation}

\section{a. Model configuration}

The two-way nested simulations of Hurricane Harvey were generated using version 3.9.1 of WRF-ARW (Skamarock et al. 2008). The model domain configuration is shown in Fig. 8 and the "tropical" physics suite options are summarized in detail in Table S2 in the online supplemental material and are similar to previous studies using WRF-ARW for hurricane applications (Davis et al. 2008). The results presented herein are derived from the inner model domain that used convection-allowing 4-km horizontal grid spacing (Fig. 8). The initial time of 1200 UTC 23 August was chosen because Harvey 1) had emerged into the Gulf of Mexico from the Yucatan Peninsula earlier in the day and 2) was upgraded to tropical depression status in HURDAT2 but had not yet began a period of rapid intensification.

\section{b. Control simulation}

Prior to examination of the soil moisture sensitivity simulations, it is necessary to compare the rainfall, track, and intensity of Harvey in the control (CTL) experiment with the observations (Fig. 9). CTL shows a left-of-track error with Harvey making landfall in Corpus Christi, Texas, as compared with farther northeast near Rockport in observations (Fig. 9a). Also, CTL shows Harvey making landfall at 2100 UTC 25 August which is about $6 \mathrm{~h}$ earlier than observed. CTL was able to capture Harvey's rapid intensification in the 36-h period prior to landfall (Fig. 9b). The simulated structure of Harvey just after landfall as depicted by outgoing longwave radiation at 2245 UTC 25 August shows a well-defined eye structure consistent with observations (Fig. 8 inset). Despite the rapid intensification of Harvey in the CTL, the intensity was too low throughout the simulation with the sea level pressure at landfall about $30 \mathrm{hPa}$ too high and the maximum nearsurface wind speed about $10 \mathrm{~m} \mathrm{~s}^{-1}$ too low (Fig. 9b). Previous studies have shown that a low intensity bias in numerical model forecasts of tropical systems in the Gulf

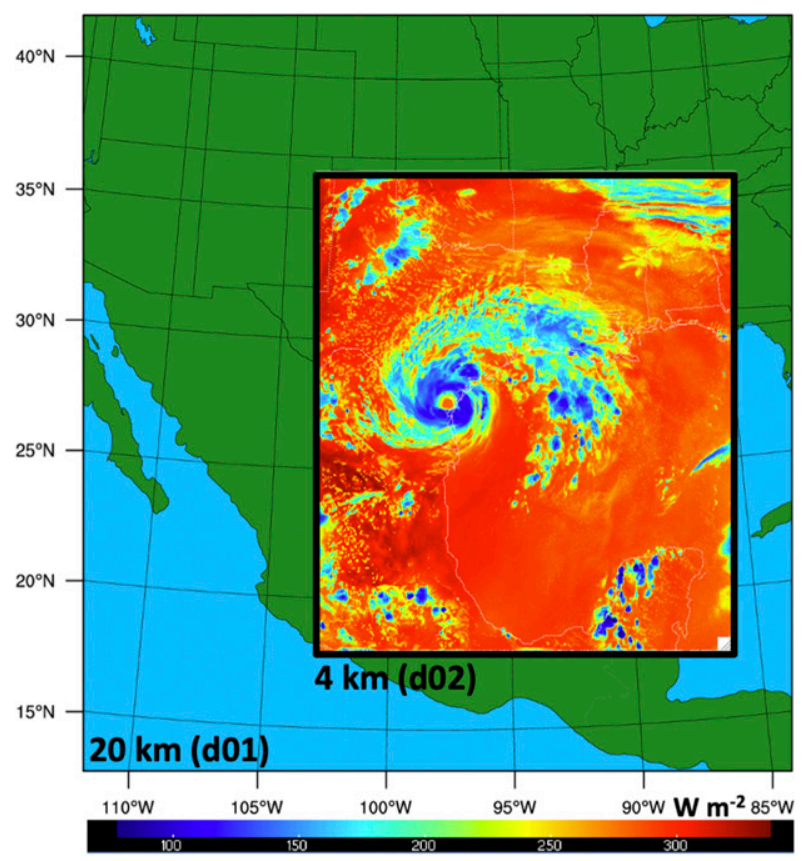

FIG. 8. Geographical locations of the WRF-ARW domains. The horizontal grid spacing is $20 \mathrm{~km}$ on the parent domain (d01) and $4 \mathrm{~km}$ on the inner domain (d02). Outgoing longwave radiation (shaded according to the color bar; $\mathrm{W} \mathrm{m}^{-2}$ ) is shown from the inner domain in the CTL simulation verifying at 2200 UTC 25 Aug 2017.

of Mexico can contribute to left-of-track errors in the region (Galarneau and Hamill 2015), similar to the CTL simulation.

Despite the lower intensity and landfall farther south along the Texas coast, CTL still produced a recordbreaking rainstorm in the Texas coastal plain with widespread accumulated rainfall over $1000 \mathrm{~mm}$ during 1200 UTC 23-30 August 2017 (Fig. 9a). A bulk of the heaviest rainfall accumulations were displaced slightly farther southwest compared to observations, consistent with the left-of-track error in the simulation. CTL also produced an area of accumulated rainfall over $1000 \mathrm{~mm}$ near Houston, consistent with observations. Inspection of model-derived radar reflectivity and near-surface wind, potential temperature, and frontogenesis shows a similar evolution to observations (Fig. 10). Bands of intense thunderstorms repeatedly developed on the eastern flank of slow-moving Harvey during and after landfall, expanding into a large rain shield just inland of a frontogenetical coastal front (Figs. 10b,c). The coastal frontogenesis appears to be important in maintaining tropical rains in the Houston, Texas, area after the main convective bands moved farther east on 28 August (Fig. 10d).

In summary, the structure and evolution Harvey in CTL appears to represent the observed system very well by producing track errors $<75 \mathrm{~km}$ at the time of landfall 
a) HURDAT and CTL track and rainfall

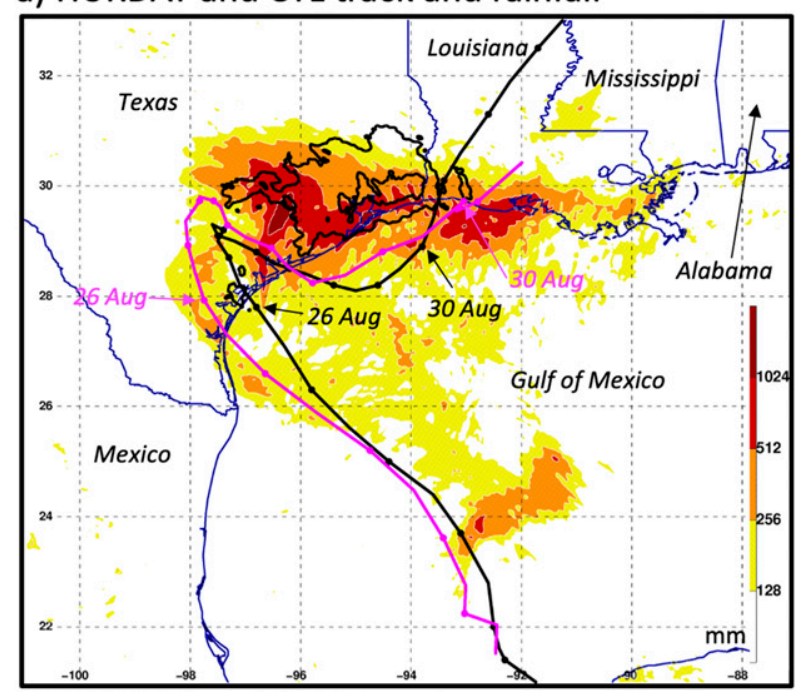

b) HURDAT and CTL intensity

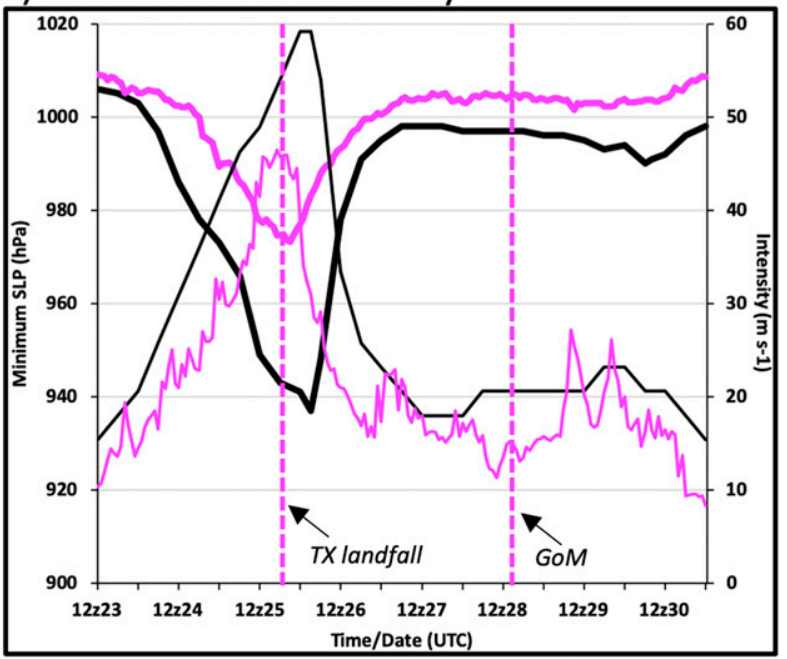

FIG. 9. (a) CTL total accumulated precipitation (shaded according to the color bar; $\mathrm{mm}$ ) and Stage-IV total accumulated precipitation (solid black contours at 512 and $1024 \mathrm{~mm}$ ) for 1200 UTC 23-30 Aug 2017 overlaid with the CTL (magenta) and HURDAT2 (black) tracks for Harvey. Positions are marked at 0000 and 1200 UTC with color-filled circles. (b) Time series of minimum sea level pressure (thick lines; $\mathrm{hPa}$ ) and intensity (thin lines; $\mathrm{m} \mathrm{s}^{-1}$ ) for CTL (magenta) and HURDAT2 (black). Landfall on the Texas coast and reemergence into the Gulf of Mexico are marked by the vertical magenta dashed lines in (b).

near 2100 UTC 25 August $(69 \mathrm{~h}$ into the model integration), which is less than the $150-\mathrm{km}$ baseline forecast error for a 72-h forecast established as part of the Hurricane Forecast Improvement Program (Gall et al. 2014). While the intensity of Harvey was underdone in CTL, rapid intensification of Harvey occurred in the 36-h period prior to landfall. Last, although the details of where the heaviest rains fell in the Texas coastal plain in
CTL differed from observations, in a bulk sense CTL produced a record-breaking rainstorm with a slowmoving Harvey with an area-mean rainfall of $263.1 \mathrm{~mm}$ and area-maximum rainfall of $1406.0 \mathrm{~mm}$ (as compared with 234.8 and $1376.3 \mathrm{~mm}$ in the Stage-IV rainfall analysis) (Table 1).

The initial soil moisture content in CTL was derived from the GFS analysis at 1200 UTC 23 August 2017. Comparing the GFS near-surface $0-10-\mathrm{cm}$ soil moisture content with the NASA L4SMAP 0-5-cm soil moisture content at 1200 UTC 23 August 2017 (cf. Figs. $1 \mathrm{~b}$ and $11 \mathrm{a}$ ) reveals reasonably good agreement, which gives confidence in using the GFS soil moisture as the initial condition. Integrating CTL forward through 1200 UTC 27 August reveals a dramatic increase in soil moisture over much of southeast Texas similar to NASA L4SMAP (cf. Figs. 1c and 11b) illustrating how CTL properly moistened the soils during the Harvey rainstorm. Because CTL produced record rain amounts, increases in soil moisture, a convective morphology that resembled observations, and the key physical mechanisms that drove the heavy rains, it is adequate to use as a baseline simulation for a soil moisture sensitivity experiment.

\section{Sensitivity to soil moisture conditions}

\section{a. Experimental design}

To test the relevance of the underlying soil moisture conditions on the Harvey rainstorm, a sensitivity experiment was designed as summarized in Table 2. In addition to CTL, five perturbation simulations were generated in which in the initial soil moisture was modified and whether rainfall can modify the initial soil moisture. For the latter, the initial soil moisture condition is held constant throughout the simulation. The model configuration for each simulation is otherwise identical to CTL (recall supplemental Table S2). The first perturbation simulation used the same initial soil condition as CTL, except that the initial soil moisture content was held constant throughout the simulation (named CTLC) (Fig. 11a). Therefore, a comparison of CTL and CTLC represents the influence of increased soil moisture content due to the Harvey rainstorm on the evolution of the Harvey rainstorm itself.

Hypothetical soil moisture initial conditions were also tested in the perturbation simulations to to assess if Harvey's evolution would have been impacted by fully saturated or very dry soil moisture. For dry soils, the initial soil moisture was set to $0.005 \mathrm{~m}^{3} \mathrm{~m}^{-3}$ over all land regions in the convection-allowing domain (d02; Fig. 8). For the simulation in which the initially dry soils were allowed to evolve (named DRY), the soils moistened in 

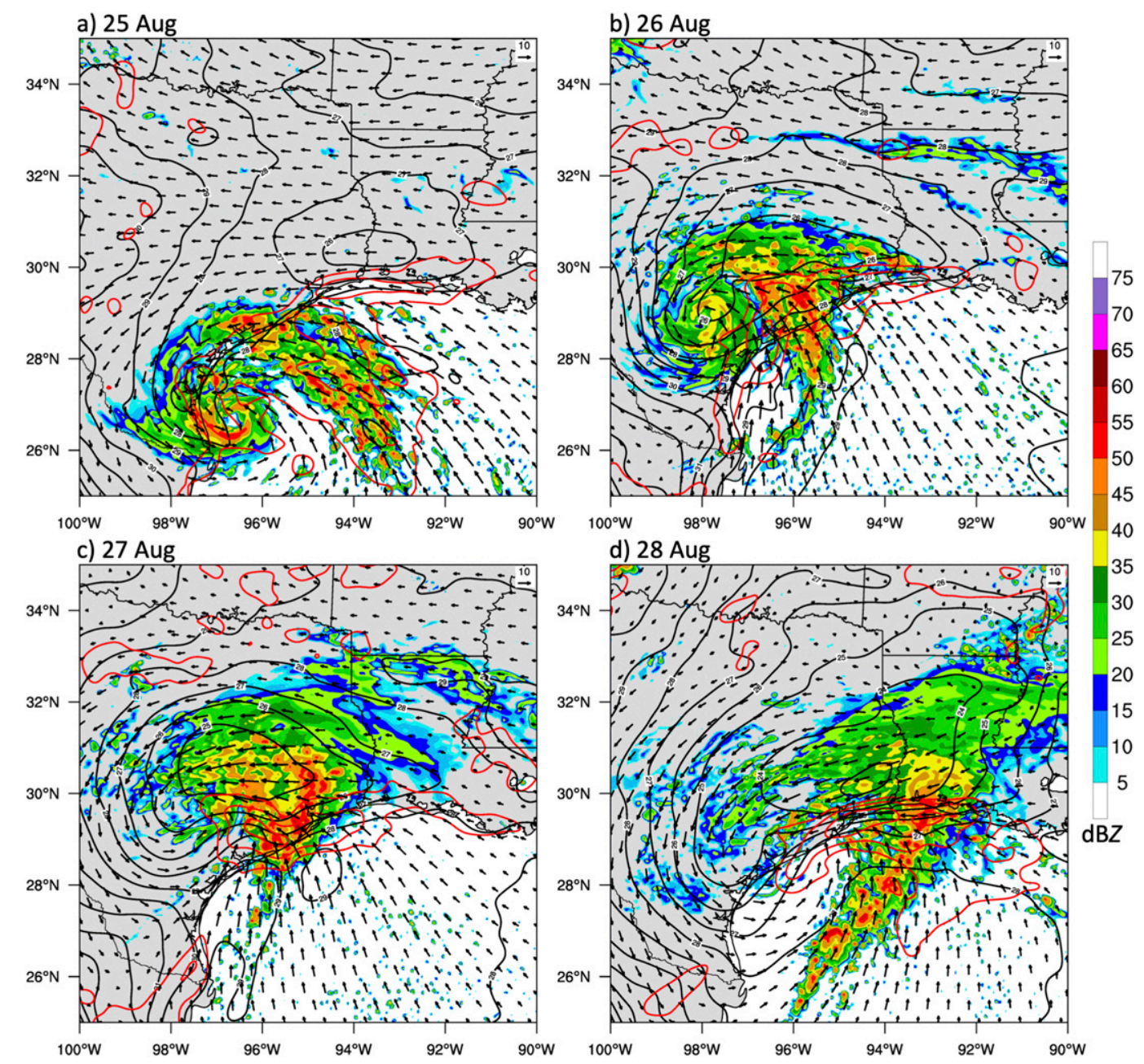

FIG. 10. WRF-ARW CTL simulation composite reflectivity (shaded; dBZ) at 1200 UTC and daily mean wind (arrows; $\mathrm{m} \mathrm{s}^{-1}$ ), potential temperature (solid black contours every $1^{\circ} \mathrm{C}$ ), and Petterssen frontogenesis [solid red contours at $4,7,10,20,40$, and $80^{\circ} \mathrm{C}(100 \mathrm{~km})^{-1}(3 \mathrm{~h})^{-1}$ ] averaged over the lowest five model levels on (a) 25 , (b) 26 , (c) 27, and (d) 28 Aug 2017.

south Texas where Harvey tracked (Fig. 11c). Another simulation was generated in which the initially dry soils were held constant (named DRYC). A similar set of perturbation simulations were generated for fully saturated soil moisture conditions (named SAT and SATC). While the soil moisture for the initially saturated soils in SAT decreased during the simulation (Fig. 11d), much of south Texas maintained very moist soils compared to CTL and DRY.

The hypothetical initial soil moisture conditions in DRY, DRYC, SAT, and SATC-in which homogeneous soil moisture was prescribed over all land surfaces in a large geographical region-are unlikely to ever occur in reality. However, there are situations in which the soil moisture can be anomalously wet or dry over a large region based on the seasonal climate variations in rainfall and temperature. For instance, Evans et al. (2011) found that the inland reintensification of Tropical Storm Erin (2007) was sensitive to the anomalously wet soils in Oklahoma due to higher than normal rainfall amounts in the preceding months (see also Schumacher and Davis 2010). Conversely, anomalously dry soils have been documented over very large geographical regions during extended heat waves and droughts. In cases such as the heat wave and drought in the summer of 1980, sensible heating over dry soils contributed to a reduction of rainfall in the southern Great Plains because of a deeper and drier PBL relative to climatology (Hao and Bosart 1987). The drought in Texas and northern Mexico in 2010-11 (e.g., Seager et al. 2014) is a more recent example of how soils can become anomalously dry over a very large geographical region. These dry conditions may have 
TABLE 1. Average and maximum total accumulated rainfall $(\mathrm{mm})$ in a region in southeast Texas for 1200 UTC 23-30 August 2017.

\begin{tabular}{|c|c|c|c|}
\hline Description & Area avg $(\mathrm{mm})$ & Area $\max (\mathrm{mm})$ & Region \\
\hline Stage-IV rainfall & 234.8 & 1376.3 & $28^{\circ}-32^{\circ} \mathrm{N}, 98^{\circ}-92^{\circ} \mathrm{W}$ \\
\hline CTL & 263.1 & 1406.0 & $27^{\circ}-31^{\circ} \mathrm{N}, 98^{\circ}-92^{\circ} \mathrm{W}$ \\
\hline DRY & 246.4 & 1288.5 & $26.5^{\circ}-30.5^{\circ} \mathrm{N}, 100^{\circ}-94^{\circ} \mathrm{W}$ \\
\hline SAT & 256.4 & 1362.9 & $27^{\circ}-31^{\circ} \mathrm{N}, 98^{\circ}-92^{\circ} \mathrm{W}$ \\
\hline CTLC & 267.1 & 1335.9 & $27^{\circ}-31^{\circ} \mathrm{N}, 98^{\circ}-92^{\circ} \mathrm{W}$ \\
\hline DRYC & 248.4 & 1402.3 & $26.5^{\circ}-30.5^{\circ} \mathrm{N}, 100^{\circ}-94^{\circ} \mathrm{W}$ \\
\hline SATC & 264.7 & 1205.0 & $27^{\circ}-31^{\circ} \mathrm{N}, 98^{\circ}-92^{\circ} \mathrm{W}$ \\
\hline
\end{tabular}

contributed to the rapid dissipation of Tropical Storm Don (2011) after landfall on the Texas coastline (Brennan 2011).

The following subsections will describe how varying soil moisture conditions contributed to differences in track, intensity, and rainfall of Harvey compared to CTL.

\section{b. Track}

The track of Harvey in DRY and SAT is shown in Figs. 12a and 12c. Similar to CTL, a persistent left-oftrack error (relative to HURDAT2) developed early in the simulation and persisted through Harvey's landfall and near stationarity in southeast Texas. The track of Harvey in SAT and CTL are almost indistinguishable, with Harvey making landfall slightly farther northeast along the Texas coastline in SAT (cf. Figs. 9a and 12c). The DRY simulation produced a much different track for Harvey compared to SAT and CTL, with a landfall farther southwest along the Texas coastline (Fig. 12a). Harvey reemerged in the Gulf of Mexico on 28 August in CTL and SAT but failed to do so in DRY, instead remaining in south Texas through the rest of the simulation. Examination of the perturbation simulations in which the soil moisture was held constant showed a similar track behavior for Harvey (Figs. 13a,c,e). The CTLC and SATC simulations are very similar to the CTL and SAT simulations, respectively (Figs. 9a, 12a,c, and 13a,e). The DRYC simulation shows a similar track behavior as DRY, with Harvey making landfall farther southwest (Figs. 12a and 13c).

While the simulated tracks of Harvey in CTL, CTLC, SAT, and SATC show little sensitivity to the underlying soil moisture conditions, the relative differences in track in DRY (and DRYC) suggests that the Harvey track was influenced by the hypothetical dry soil condition. In comparing the simulated tracks in CTL and DRY, the differences in Harvey's motion began around $36 \mathrm{~h}$ into the simulations at 0000 UTC 25 August (Fig. 13a). A steering layer flow analysis comparing CTL and DRY is shown in Fig. 14. In both simulations, Harvey's steering layer flow was defined as the $850-200$-hPa layer using a radius of $2^{\circ}$. Since the definition of the steering flow depth and radius is identical in both simulations, forward motion differences in CTL and DRY are attributed to differences in environment wind only (cf. Equation 10 in Galarneau and Davis 2013). The DRY simulation had a $0.6 \mathrm{~m} \mathrm{~s}^{-1}$ southwestward motion perturbation relative to CTL, consistent with a $1.2 \mathrm{~m} \mathrm{~s}^{-1}$ southsouthwestward 850-200-hPa environment wind difference that is balanced by a $0.6 \mathrm{~m} \mathrm{~s}^{-1}$ north-northwestward residual $^{3}$ (Fig. 14a).

The 850-200-hPa south-southwestward environment wind perturbation in DRY was associated with a deep layer northerly and a shallower $850-700-\mathrm{hPa}$ northeasterly perturbation (Fig. 14b). The environment wind difference was associated with an anticyclonic perturbation in southern Oklahoma and southern Texas and a cyclonic perturbation in the eastern Gulf of Mexico in DRY (Fig. 14c). The southwestward environment wind perturbation in the shallower $850-700-\mathrm{hPa}$ layer was with anticyclonic and cyclonic wind perturbations in the same regions as the deeper 850-200-hPa layer, except the circulations were more intense (Figs. 14a,d). The anticyclonic circulation in southern Oklahoma is located at the core of a positive 700-hPa geopotential height perturbation (averaged for the 24-h period centered on 0000 UTC 25 August) in much of Texas and Oklahoma and extending east toward the Mississippi valley (Fig. S5a in the online supplemental material). The positive $700-\mathrm{hPa}$ height differences were associated with a $0.7 \mathrm{~m} \mathrm{~s}^{-1}$ southwestward geostrophic wind perturbation in the $850-700-\mathrm{hPa}$ layer in Harvey's steering flow, suggesting that the motion differences in DRY versus CTL were driven in part by a more robust anticyclone in the southern Great Plains in DRY (Fig. 14a).

The development of a positive 700-hPa geopotential height perturbation in the southern Great Plains was driven by increased surface sensible heating leading to

\footnotetext{
${ }^{3}$ The residual wind is likely associated with errors in the divergent and rotational wind components introduced by inverting the vorticity and divergence on a model grid domain that covers a geographical region near or smaller than the Rossby radius of deformation (e.g., Galarneau and Davis 2013).
} 

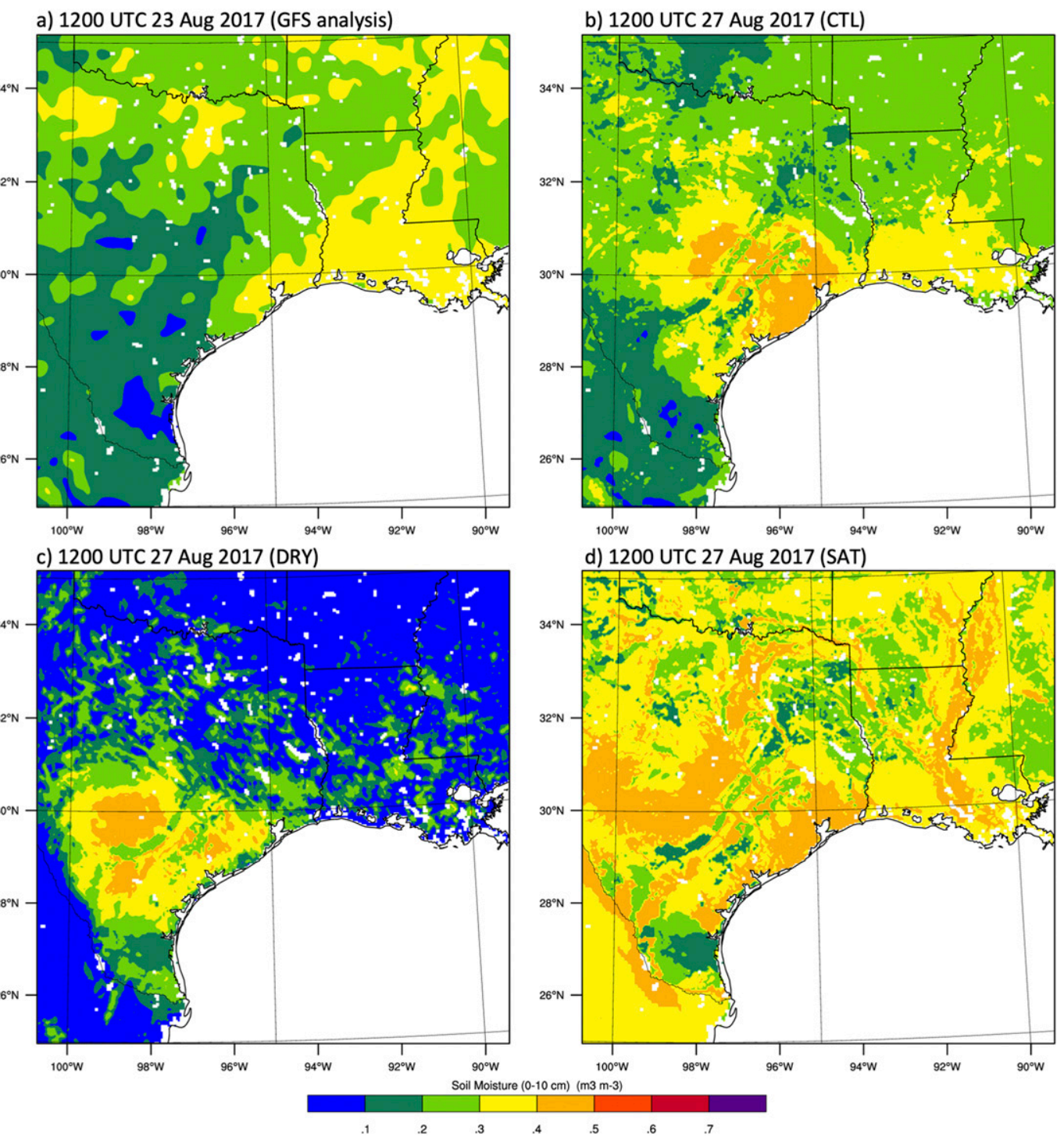

FIG. 11. Volumetric soil moisture content (shaded according to the color bar; $\mathrm{m}^{3} \mathrm{~m}^{-3}$ ) in the 0-10-cm layer for the (a) GFS analysis at 1200 UTC 23 Aug and (b) CTL, (c) DRY, and (d) SAT at 1200 UTC 27 Aug 2017.

increased 1000-700-hPa thickness over the dry soils (Fig. S5b). Point soundings in southeast Oklahoma (point A) and closer to the coast in southeast Texas (point B) showed that DRY developed a deeper and warmer PBL relative to CTL, likely as a result of increase surface sensible heat fluxes (Figs. S5c,d). The warmer and deeper PBL was consistent with increased $700-\mathrm{hPa}$ geopotential heights in the southern Great

TABLE 2. Summary of soil moisture configurations for the suite of WRF-ARW simulations. The soil moisture initial condition is set over all land regions in $\mathrm{d} 02$.

\begin{tabular}{cll}
\hline \hline Simulation & \multicolumn{1}{c}{ Soil moisture initial condition } & Soil moisture constant? \\
\hline CTL & 1200 UTC 23 Aug 2017 GFS analysis & No \\
CTLC & Same as CTL & Yes (rain does not modify soil) \\
SAT & Saturated soil & Same as CTL \\
SATC & Same as SAT & Same as CTLC \\
DRY & Dry soils & Same as CTL \\
DRYC & Same as DRY & Same as CTLC \\
\hline
\end{tabular}


a) HURDAT and DRY track and rainfall

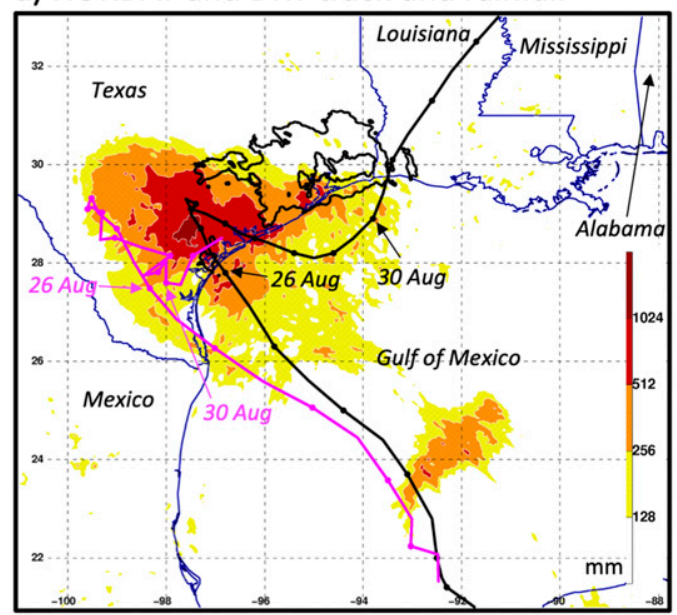

b) HURDAT and DRY intensity

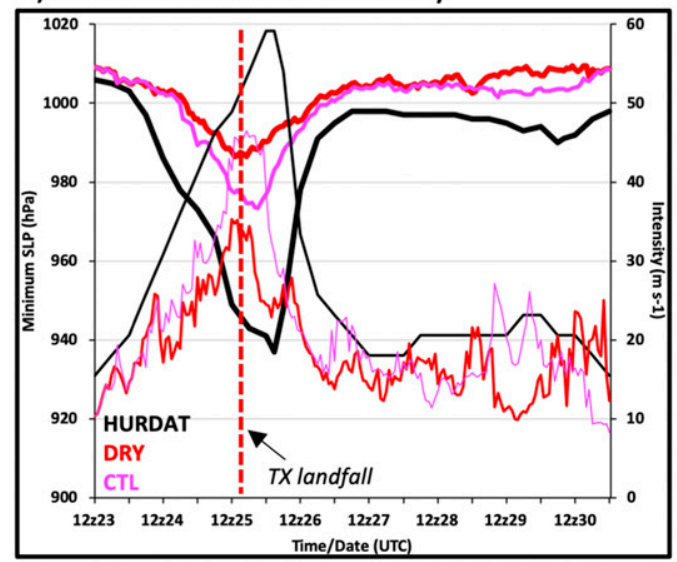

c) HURDAT and SAT track and rainfall

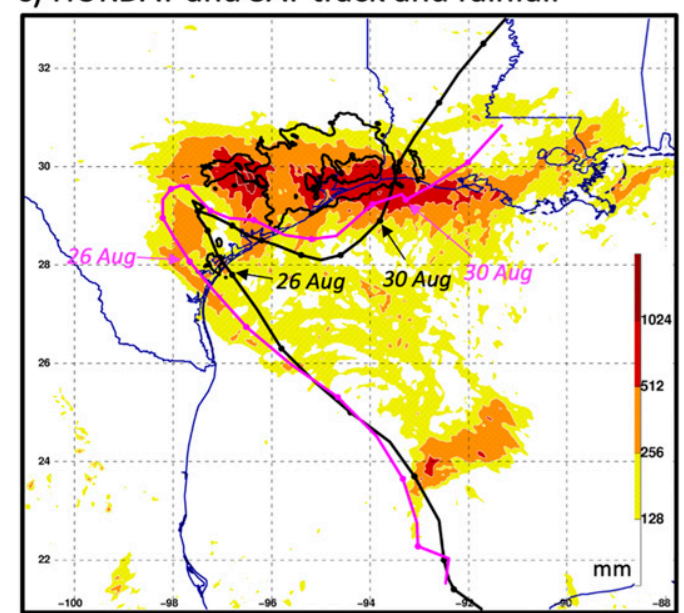

d) HURDAT and SAT intensity

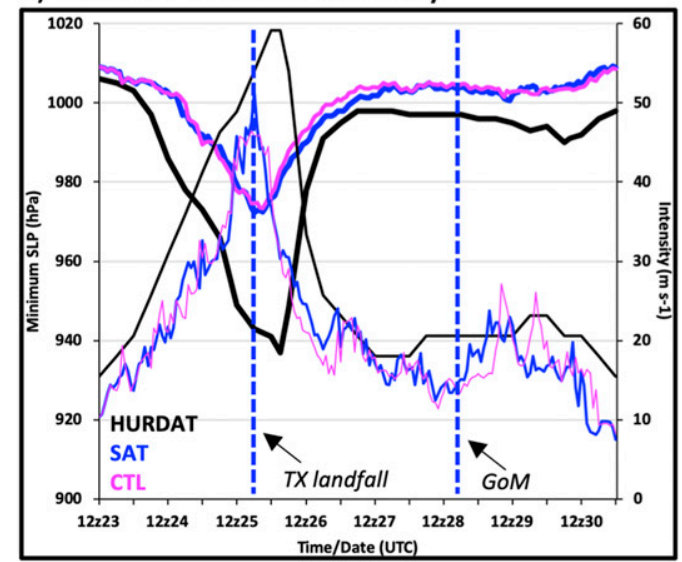

FIG. 12. (a) DRY and (c) SAT total accumulated precipitation (shaded according to the color bar; mm) and Stage-IV total accumulated precipitation (solid black contours at 512 and $1024 \mathrm{~mm}$ ) for 1200 UTC 23-30 Aug 2017 overlaid with the DRY [in (a)] and SAT [in (c)] tracks (magenta) and HURDAT2 track (black) for Harvey. Positions are marked at 0000 and 1200 UTC with color-filled circles. Also shown are time series of minimum sea level pressure (thick lines; hPa) and intensity (thin lines; $\mathrm{m} \mathrm{s}^{-1}$ ) for (b) DRY (red), (d) SAT (blue), CTL (magenta), and HURDAT2 (black). Landfall on the Texas coast and reemergence into the Gulf of Mexico are marked by the vertical dashed lines in (b) and (d).

Plains in DRY, contributing in part to steering Harvey farther south into Texas. A similar 700-hPa geopotential height and environment wind perturbation was responsible for steering Harvey farther south in Texas in DRYC (not shown).

\section{c. Intensity}

As Harvey meandered in southeast Texas prior to reemerging in the Gulf of Mexico on 28 August, it remained at tropical storm intensity in CTL (Fig. 9b). There was variability in the winds after spindown of Harvey in the first $12-24 \mathrm{~h}$ after landfall, peaking at a maximum value of $23 \mathrm{~m} \mathrm{~s}^{-1}$ at 0000 UTC 27 August. The differences in mean wind speed at time of peak intensity before and after landfall are summarized in Table S3 in the online supplemental material. The mean intensity for each simulation for 1200 UTC 26-0000 UTC 28 August (after landfall) is near tropical storm intensity with CTL at $18.2 \mathrm{~m} \mathrm{~s}^{-1}$, and DRY, DRYC, and CTLC $1-2 \mathrm{~m} \mathrm{~s}^{-1}$ lower than CTL and SAT and SATC $1-2 \mathrm{~m} \mathrm{~s}^{-1}$ higher than CTL. It appears that the simulations with drier soils have slightly weaker near-surface wind speeds on average than do the simulations with wetter soils. The differences are small (and are in part a function of the intensity just prior to landfall), however, given that each simulation maintained Harvey near tropical storm intensity.

Larger differences in time-mean near-surface wind speeds are apparent prior to landfall. The $6 \mathrm{~h}$ mean intensity (time period centered on maximum intensity) 
a) HURDAT and CTLC track and rainfall

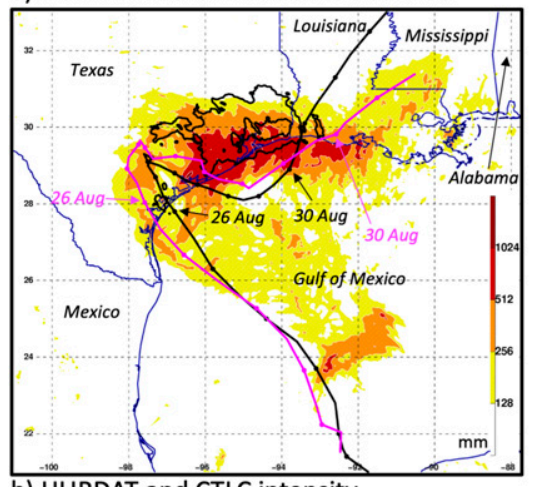

b) HURDAT and CTLC intensity

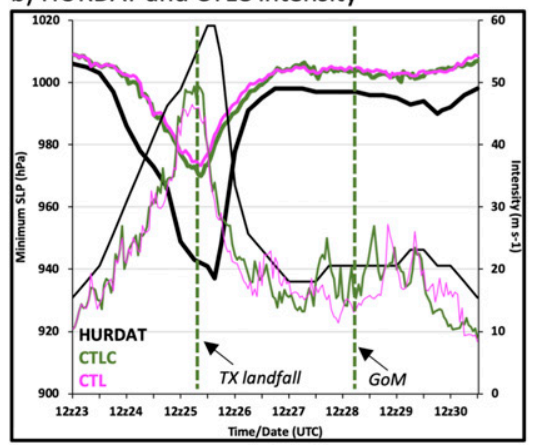

c) HURDAT and DRYC track and rainfall

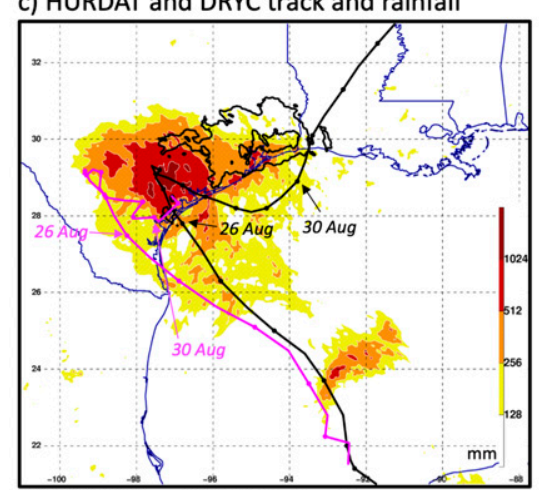

d) HURDAT and DRYC intensity

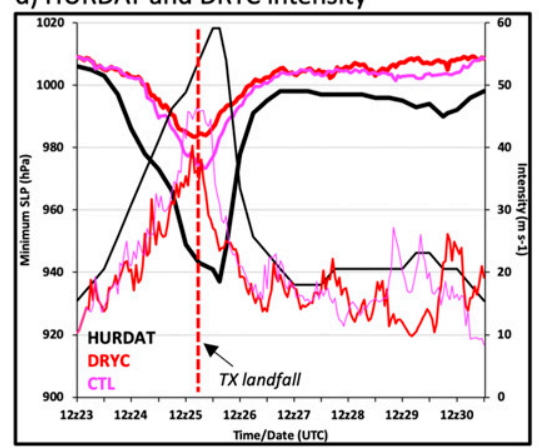

e) HURDAT and SATC track and rainfall

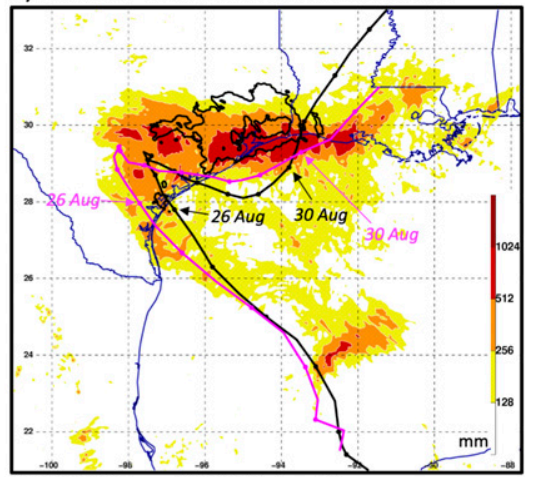

f) HURDAT and SATC intensity

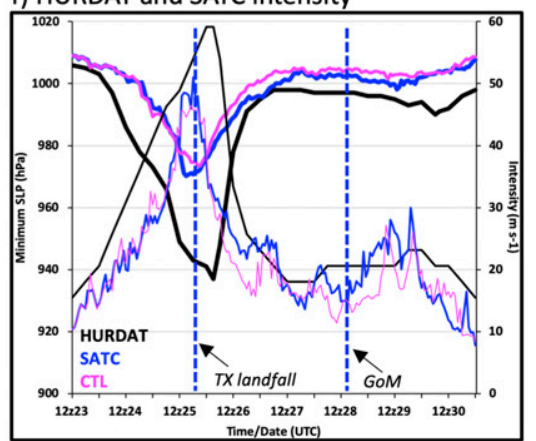

FIG. 13. (a) CTLC, (c) DRYC, and (e) SATC total accumulated precipitation (shaded according to the color bar; mm) and Stage-IV total accumulated precipitation (solid black contours at 512 and $1024 \mathrm{~mm}$ ) for 1200 UTC 23-30 Aug 2017 overlaid with the (a) CTLC, (c) DRYC, and (e) SATC (magenta) and HURDAT2 (black) tracks for Harvey. Positions are marked at 0000 and 1200 UTC with colorfilled circles. Also shown are time series of minimum sea level pressure (thick lines; hPa) and intensity (thin lines; $\mathrm{m} \mathrm{s}^{-1}$ ) for (b) CTLC (green), (d) DRYC (red), and (f) SATC (blue) along with CTL (magenta) and HURDAT2 (black). Landfall on the Texas coast and reemergence into the Gulf of Mexico are marked by the vertical dashed lines in (b), (d), and (f).

among the simulations prior to landfall shows that the DRY and DRYC systems were $\sim 10 \mathrm{~m} \mathrm{~s}^{-1}$ weaker than the CTL simulation (Table S3). The SAT, SATC, and CTLC simulations were within $3 \mathrm{~m} \mathrm{~s}^{-1}$ of CTL. To explore the reasons why Harvey was relatively weaker in DRY and DRYC, the evolution of Harvey in the Gulf of Mexico in DRY and CTL are compared. The time series of area-mean relative vorticity at the 850 - and $500 \mathrm{hPa}$ layers (averaged in a 75-km radius centered on Harvey) is shown in Fig. 15a. Both CTL and DRY intensified Harvey at a similar rate except for 1200-1800 UTC 24 August (24-36h). The development of Harvey in DRY was temporarily interrupted, and was the main contributor to the relatively weaker system at landfall along the Texas coastline (Figs. 12a,b). The interruption of Harvey's intensification occurred as the area-mean convective available potential energy (CAPE) decreased to near $1000 \mathrm{~J} \mathrm{~kg}^{-1}$, as compared to $\sim 2000 \mathrm{~J} \mathrm{~kg}^{-1}$ in $\mathrm{CTL}$ (Fig. 15b). At the same time, the number of updrafts at 850 and $500 \mathrm{hPa}$ within $75 \mathrm{~km}$ of Harvey's center became much lower in DRY compared to CTL (Fig. 15c). The reduction of updrafts near the center of Harvey in DRY represented a weakening of convection near the center, in concert with a reduction of CAPE.

Examination of the distribution of convection relative to Harvey's center just prior to the interruption of intensification showed a cluster of intense convection at the center in both CTL and DRY at 0800 UTC 24 August (20h) (Figs. 16a,d). The center of Harvey at 500 and $850 \mathrm{hPa}$ are aligned vertically at this time as shown by the potential vorticity (PV), with a second region of positive $\mathrm{PV}$ at $500 \mathrm{hPa}$ extending northeastward from the center. The distribution of PV at these levels resulted in northwesterly 900-500-hPa vertical wind shear in the region of convection in both simulations (Figs. 16b,e). The convection near Harvey's center in DRY produced a strong cold pool near the surface with $2-\mathrm{m}$ potential temperature $\sim 5 \mathrm{~K}$ lower than CTL. The development of a strong cold pool beneath Harvey resulted in a lowering of the CAPE and cessation of convection near the center (Figs. 15c and 16c,f).

The strong cold pool in DRY appears to be linked to drier air in the environment on the east side of Harvey. Comparison of DRY and CTL at 1800 UTC 23 August (6h) shows that 500-hPa PV and 925-850-hPa layer-mean water vapor mixing ratio are very similar near the center of Harvey 

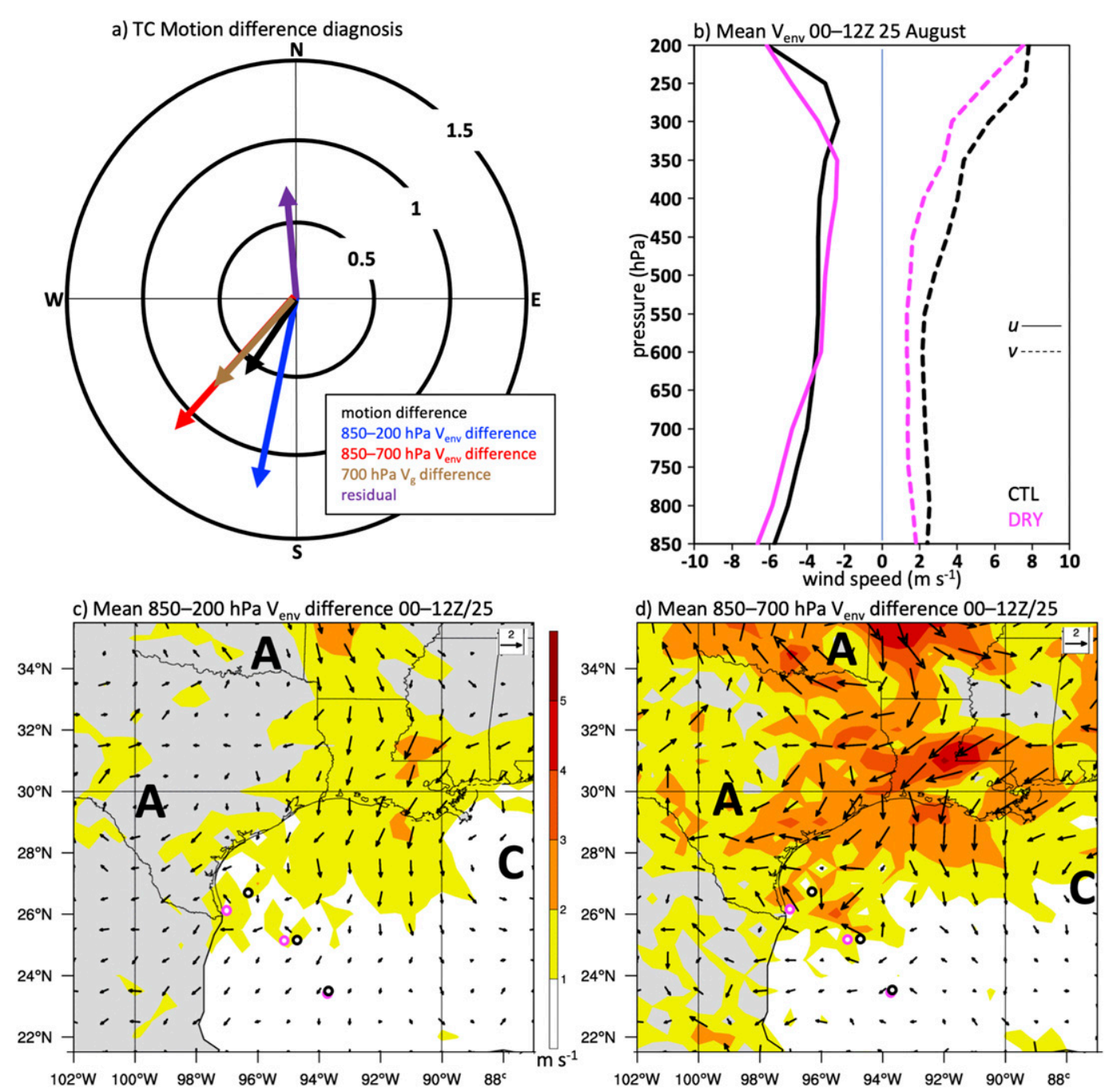

FIG. 14. (a) Time-mean tropical cyclone motion difference diagnostic terms (vector arrows; $\mathrm{m} \mathrm{s}^{-1}$ ) for DRY minus CTL at 0000-1200 UTC 25 Aug 2017. The arrows for each term are color coded by the key. The residual is the motion difference (black) minus the 850-200-hPa environment wind (blue) difference. The 850-700-hPa environment wind (red) and 700-hPa geostrophic wind (brown) difference are also shown. (b) Vertical profile of the time mean environment wind ( $\mathrm{m} \mathrm{s}^{-1}$; zonal wind solid; meridional wind dashed) at 0000-1200 UTC 25 Aug for CTL (black) and DRY (magenta). Also shown are time-mean environmental wind difference (arrows with magnitude shaded; $\mathrm{m} \mathrm{s}^{-1}$ ) between DRY and CTL (DRY minus CTL) at 0000-1200 UTC 25 Aug in the (c) 850-200- and (d) 850-700-hPa layers. Anticyclonic and cyclonic circulation differences are labeled "A" and "C," respectively. Storm locations at 1200 UTC 24, 0000 UTC 25, and 1200 UTC 25 Aug in are marked by white-filled circles outlined according to the key in (b).

(Fig. 17a). In the Yucatan Peninsula, however, drier soils in DRY have resulted in lower water vapor mixing ratio in the 925-850-hPa layer. By 0800 UTC 24 August (20 h), the plume of drier air moved northwestward to east of Harvey in DRY (Fig. 17b). Backward air parcel trajectories ${ }^{4}$

\footnotetext{
${ }^{4}$ Air parcel trajectories were computed using the Read/Interpolate/ Plot software package (https://www2.mmm.ucar.edu/wrf/users/docs/ ripug.htm) by linearly interpolating the hourly velocity data to a 10 -min trajectory time step.
}

released at $850 \mathrm{hPa}$ at 0800 UTC 24 August near Harvey originated below $850 \mathrm{hPa}$ in the Yucatan Peninsula at 1800 UTC 23 August (Fig. 17b). While the trajectories in DRY underwent deeper ascent in the 6-12 $\mathrm{h}$ period as they departed the Yucatan, they subsequently decended and remained significantly drier relative to the trajectories in CTL (Fig. 17c). In all, these results suggest that the more intense cold pool likely developed in reponse increased evaporation of hydrometeors as the drier air from over the Yucatan Peninsula was entrained into Harvey's circulation. 
a) 850 and $500 \mathrm{hPa} \bar{\zeta}$

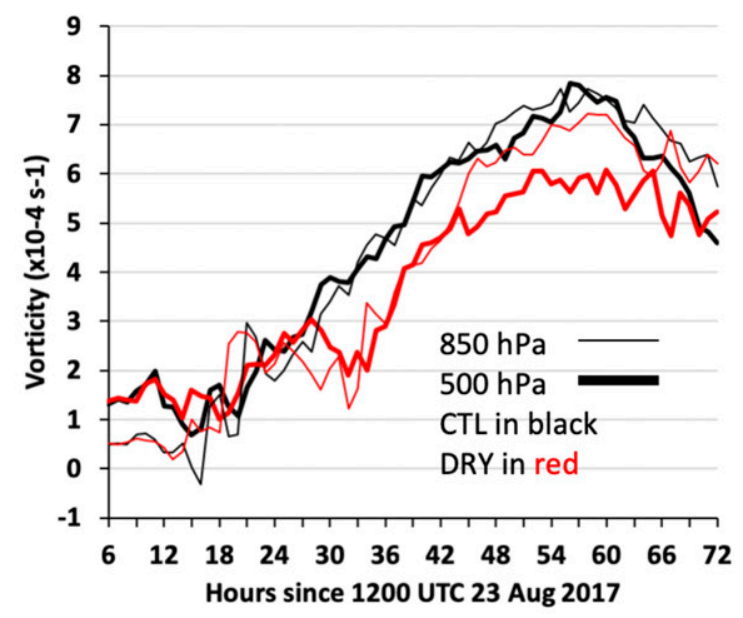

b) Area-mean CAPE and area-maximum CAPE

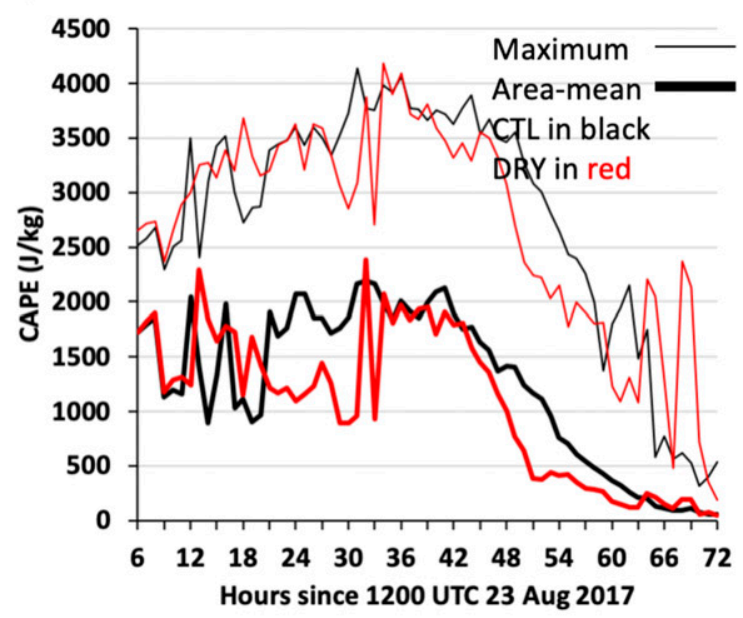

c) 850 and $500 \mathrm{hPa}$ updrafts

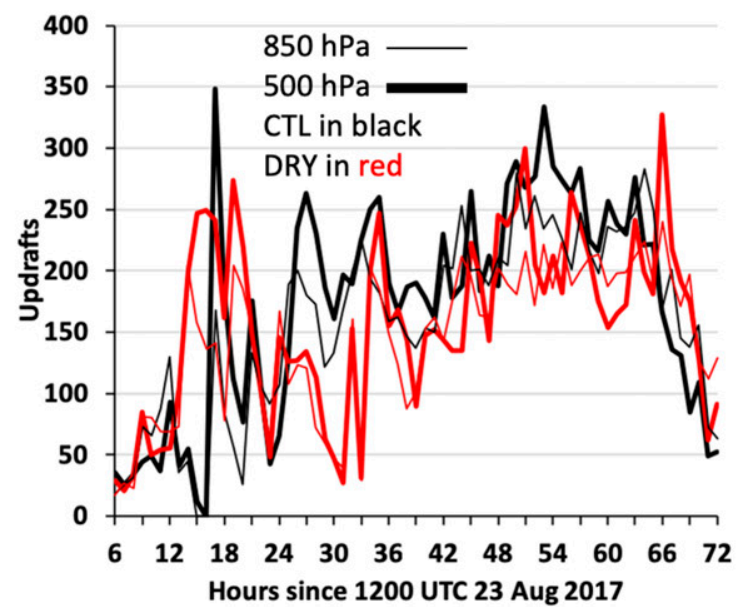

FIG. 15. Quasi-Lagrangian time series of (a) area-mean 500(thick line) and 850-hPa (thin line) relative vorticity $\left(\times 10^{-4} \mathrm{~s}^{-1}\right)$, (b) area-mean (thick line) and area-maximum (thin line) maximum CAPE $\left(\mathrm{J} \mathrm{kg}^{-1}\right)$, and (c) number of grid points at 500 (thick line)

\section{d. Rainfall}

The total accumulated rainfall for 1200 UTC 2330 August 2017 for DRY and SAT is shown in Figs. 12a and $12 \mathrm{c}$. SAT produced a rainfall distribution similar to CTL, with an axis of rainfall over $1000 \mathrm{~mm}$ on the east side of Harvey and also extending northeastward along the Texas and Louisiana coastline (Figs. 9a and 12c). DRY also produced a record-breaking rainstorm with over $1000 \mathrm{~mm}$ of rain, but the heaviest rains were displaced farther southwest in Texas (Fig. 12a). The displacement of rains was linked to a more southwestward track of Harvey in DRY. The area-mean and areamaximum accumulated rainfall for the period were slightly lower in DRY and SAT compared to CTL (Table 1). Similar distributions of rainfall occurred in CTLC, SATC, and DRYC, with heaviest rains east of Harvey and extending northeastward along the Texas coastline (Figs. 13a,c,e and Table 1). In comparing the rainfall in CTL and CTLC, both simulations produced a significant rainstorm in southeast Texas with area-mean rainfall of 263.1 and $276.1 \mathrm{~mm}$ and area-maximum rainfall of 1406.0 and $1335.9 \mathrm{~mm}$, respectively (Table 1 ).

To quantify the relative role of surface evapotranspiration in the Harvey rainstorm, a total water budget is calculated following methods similar to those used by Trier et al. (2010). The local time rate of change of the vertically integrated total water $W$ is defined as

$$
\frac{\partial W}{\partial t}=\frac{1}{g} \int_{p_{1}}^{p_{2}} \nabla \cdot\left(q_{T} \mathbf{V}\right) d p+E_{v}-P
$$

where $q_{T}$ is the total water (water vapor and all hydrometeor species), $\mathbf{V}$ is the horizontal vector wind, $p$ is pressure, $p_{1}$ is $1000 \mathrm{hPa}, p_{2}$ is $300 \mathrm{hPa}, P$ is precipitation, $E_{v}$ is surface evapotranspiration from the ground and vegetation canopy, $g$ is acceleration due to gravity, and $\nabla$ is the gradient operator on a horizontal surface. The lefthand side of Eq. (4) represents the total water tendency and is calculated by computing the time derivative of the total water content output from the model simulation, thereby representing the actual water tendency (shown as $\Delta W$ in Table 3). The first term on the right-hand side of Eq. (4) represents the vertically integrated water flux convergence (IWFC). The total contributions from the

and $850 \mathrm{hPa}$ (thin line) with vertical velocity $>0.5 \mathrm{~m} \mathrm{~s}^{-1}$ for 1800 UTC 23-1200 UTC 26 Aug 2017 (6-72 h). CTL is shown in black, and DRY is given in red. All quantities are computed for the area within a 75-km radius of Harvey's center as defined by the maximum smoothed $\mathrm{PV}$ at $500 \mathrm{hPa}$. 
right-hand side represent the predicted water tendency in the budget, while the left-hand side is the actual water tendency. The terms in Eq. (4) are computed at each grid point in a $600 \mathrm{~km} \times 600 \mathrm{~km}$ region centered on Harvey in the hourly output and then area averaged. The time period in which the water budget was calculated was 0900 UTC 26-2200 UTC 27 August (69-106 h) when at least $80 \%$ of the averaging region was over land.

The accumulated tendencies from the terms in Eq. (4) for $69-106 \mathrm{~h}$ is shown in Table 3. There were slight decreases in total water in the region centered on Harvey in all of the simulations except for DRYC, which showed a small increase of $1.8 \mathrm{~mm}$. The magnitude of the change in total water [left hand side of Eq. (4)] is lower than the predicted change based on the terms on the right-hand side of Eq. (4), but resulted in residual values that were generally lower in magnitude than the other terms. The total water available for precipitation (IWFC $+E_{v}$ ) is provided primarily by IWFC, ranging from $79 \%$ to $92 \%$ of the total water contribution in the simulations. In comparing CTL and CTLC, the accumulated area-average rainfall was 78.2 and $77.7 \mathrm{~mm}$, respectively. The contribution from $E_{v}$ was slightly higher in CTL $(6.9 \mathrm{~mm})$ compared to CTLC $(6.4 \mathrm{~mm})$, but was balanced by a slightly higher contribution from IWFC for CTLC (63.9 mm) compared to CTL $(63.0 \mathrm{~mm})$. In all, it appears that the differences in surface evapotranspiration in CTL and CTLC are small, and contribute to negligible differences in accumulated rainfall in the two simulations.

The DRY and DRYC simulations produced the lowest accumulated rainfall amounts, which was consistent with lower contributions from $E_{v}$ and IWFC (Table 3). The SAT and SATC simulations produced less rainfall than CTL and CTLC despite larger contributions from $E_{v}$. The higher $E_{v}$ was balanced by lower contributions from IWFC. The time series of rain rate and IWFC is shown in Fig. S7 of the online supplemental material. In each simulation, the rain rate appears to be a function of the IWFC while Harvey was located in southeast Texas. Specifically, lower rain rates in DRY and DRYC are tied to lower IWFC. The negligible differences in rain rate for CTL and CTLC are consistent with minor differences in IWFC (Figs. S7c,d).

In all, it appears that the rainfall associated with Harvey was not directly sensitive to the underlying soil moisture condition. The underlying soil moisture and potential role of $E_{v}$ in modulating the rainfall has been documented to be important, but secondary, in other cases of landfalling tropical systems (e.g., Trenberth et al. 2007). Perhaps the scenario in which Harvey produced record-breaking rains was unique to previously documented cases. For Harvey, much of the rainfall fell as deep tropical moisture, originating over the Gulf of Mexico, was lifted along a frontogenetical coastal front. So, the physical mechanism driving the rains and the source of the atmospheric water vapor were independent of the underlying soil condition.

\section{Summary and conclusions}

This study presented an analysis of an extreme rainstorm in the Texas coastal plain that occurred in conjunction with the landfall of Hurricane Harvey on 26-30 August 2017. Over $1300 \mathrm{~mm}$ of rain accumulated from Houston to Beaumont, Texas, resulting in the most significant rainstorm on record to occur with a landfalling tropical system in the United States (Blake and Zelinsky 2018). The key ingredients that led to extreme rainfall accumulations include Harvey's slow forward motion and the collocation of deep tropical moisture and persistent synoptic and mesoscale lift.

Following landfall near Rockport, Harvey remained nearly stationary for several days before reemerging in the Gulf of Mexico on 28 August. Harvey's slowed forward motion occurred as it moved into a weak flow region near the saddle point of a deformation steering flow (e.g., Torn et al. 2018), characterized by a trough to the north and flanking ridges to the west and east. Heavy rains persisted on the east and northeast side of Harvey in the Texas coastal plain as Harvey's deep tropical moisture was lifted along a frontogenetical coastal front beneath the equatorward entrance region of an upper-level jet. The coastal front originated as a midlatitude cold front trailing southwestward from an extratropical cyclone in eastern Canada on 23 August. The overlap of deep tropical moisture and a lifting mechanism in southeast Texas lasted for several days and continued on the northwest side of Harvey on 2930 August as it emerged in the Gulf of Mexico and moved northeastward.

The climatology of rainfall associated with all landfalling tropical cyclones in the contiguous United States in 1979-2018 shows that the largest rainstorms occur with slow-moving systems. ${ }^{5}$ A subset of these rainstorms with slow-moving systems occurred as the parent tropical cyclone became embedded in a deformation steering flow pattern, similar to Harvey. One such example is Allison (2001), which was slow moving and underwent

\footnotetext{
${ }^{5}$ Kossin (2018) showed that tropical cyclone motion decreased globally during 1949-2016, and determining the relationship between this motion decrease and the frequency of interaction between tropical cyclones and deformation steering flow patterns would be an intriguing problem to examine in a future study.
} 

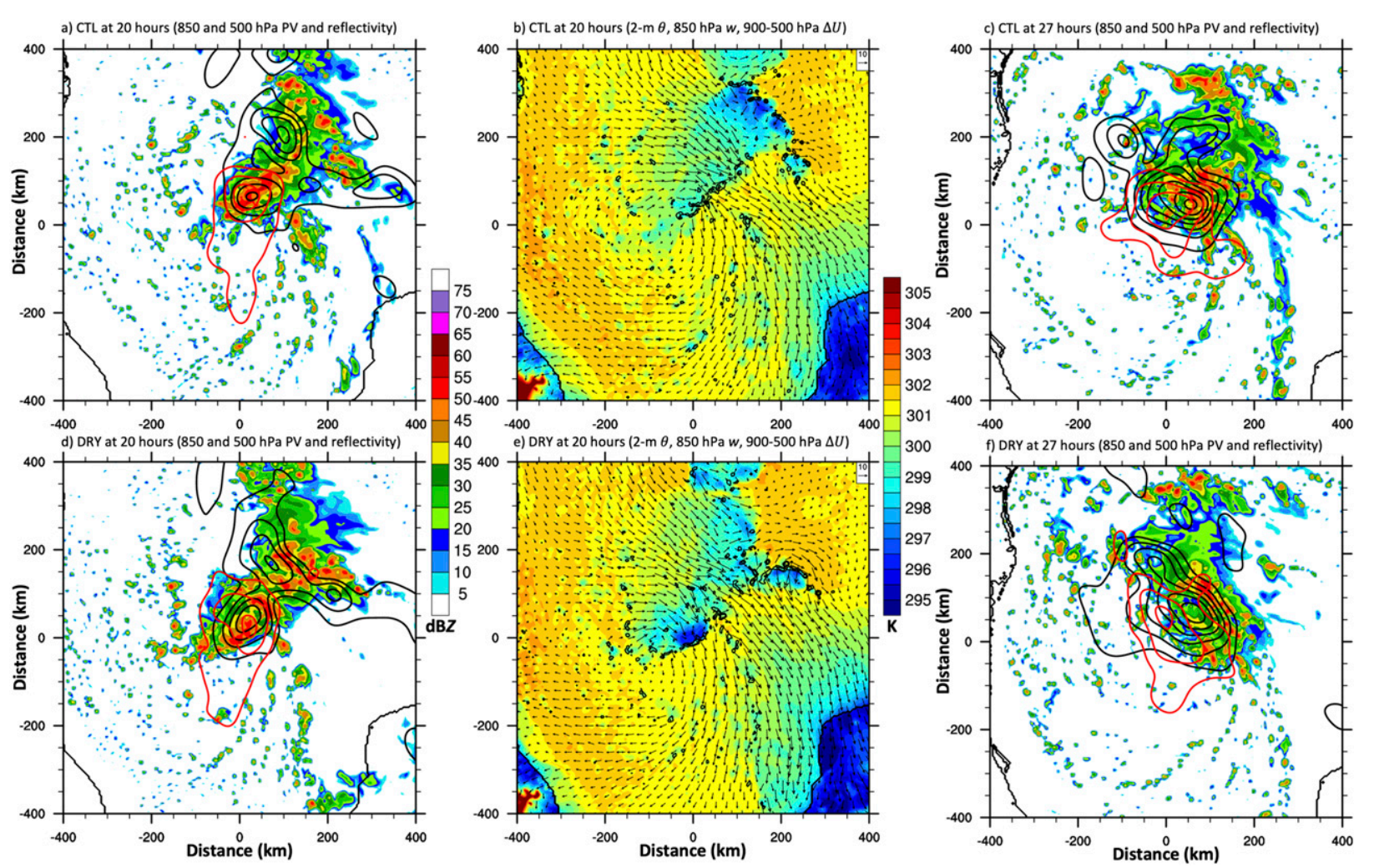

FIG. 16. Composite reflectivity (shaded; dBZ) and PV (thick contours every 0.5 PVU starting at 1.0 PVU) at 500 (black contours) and $850 \mathrm{hPa}$ (red contours) for (a) CTL and (d) DRY at 0800 UTC 24 Aug 2017 (20 h) and (c) CTL and (f) DRY at 1500 UTC 24 Aug 2017 $(27 \mathrm{~h})$. Also shown are 2-m potential temperature (shaded; K), 900-500-hPa vertical wind shear (arrows; $\mathrm{m} \mathrm{s}^{-1}$ ), and 850-hPa ascent (black contours at 1 and $3 \mathrm{~m} \mathrm{~s}^{-1}$ ) for (b) CTL and (e) DRY verifying at 0800 UTC 24 Aug 2017 (20 h). Geography is shown using thin black contours.

an abrupt change in direction of motion that allowed it produce heavy rains in the same location for an extended period. What set Harvey apart from other significant tropical cyclone rainstorms was the extended period (6 days) in which deep tropical moisture was collocated with focused synoptic and mesoscale forcing for ascent (lifting mechanism). No other tropical cyclone rainstorms in the climatology had more than 3 days in which these ingredients overlapped.

During the Harvey Texas rainstorm, marked increases in soil moisture occurred in the Texas coastal plain. Given Harvey's near stationarity, this study tested the sensitivity of the Harvey rainstorm (track, intensity, and rainfall) to varying soil moisture conditions. The track of Harvey showed sensitivity to the underlying soil moisture. The DRY and DRYC simulations produced a track located farther southwest in Texas compared to the other simulations. This difference in track occurred because a synopticscale anticyclone developed in the southern Great Plains in the first $24-48 \mathrm{~h}$ of the DRY and DRYC simulations due to increased sensible heating over dry soils that warmed and deepened the boundary layer and rapidly built the anticyclone. The anticyclone, combined with a cyclonic environment wind perturbation in the eastern Gulf of Mexico, resulted in a deep-layer northeasterly perturbation wind in Harvey's environment that resulted in a more westward course toward far south Texas. While the initially dry soils over the entire model domain is a hypothetical case unlikely to ever occur in reality, this new result highlights the importance in the treatment of soil moisture conditions particularly how it pertains to the short-range prediction of the track of tropical systems in the Gulf of Mexico.

The intensity of Harvey after landfall varied among the different soil moisture conditions, with the DRY and DRYC (SAT and SATC) simulations producing mean near-surface wind speeds $1-2 \mathrm{~m} \mathrm{~s}^{-1}$ weaker (stronger) than CTL. The differences in intensity are small, however, as each simulation maintained Harvey at or near tropical storm intensity over land. This result suggests that perhaps Harvey's environment after landfall was still influenced by the nearby ocean which lessened the importance of the underlying soil moisture condition. In 

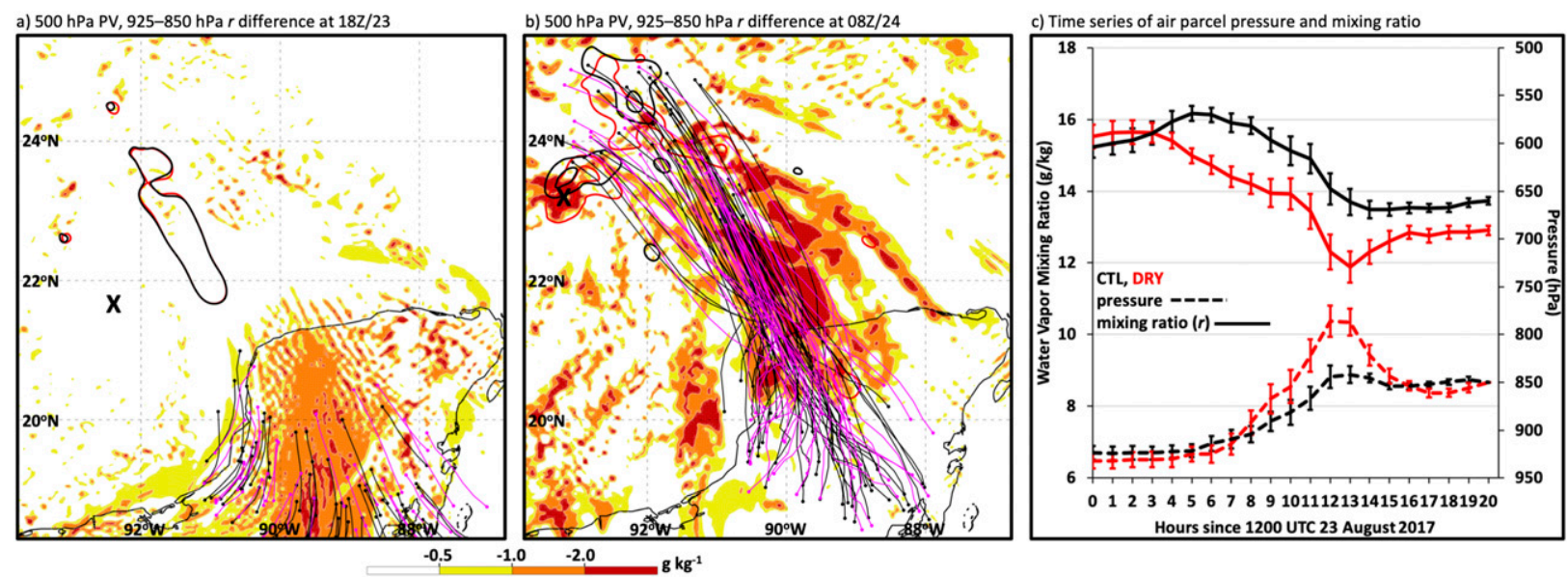

FIG. 17. The 500-hPa PV (solid contours every 2.0 PVU starting at 2.0 PVU; DRY in red and CTL in black) and 950-850-hPa layer-mean water vapor mixing ratio difference (DRY - CTL; shaded according to the color bar; $\mathrm{g} \mathrm{kg}^{-1}$ ) at (a) $1800 \mathrm{UTC} 23$ and (b) 0800 UTC 24 Aug 2017. Backward air parcel trajectories (DRY in magenta and CTL in black) were seeded near the center of Harvey at $850 \mathrm{hPa}$ at $0800 \mathrm{UTC} 24 \mathrm{Aug}$. A subset of the air parcel trajectories that originated below $850 \mathrm{hPa}$ in the Yucatan Peninsula at 1200 UTC 23 Aug is shown, with the portion of the air parcel trajectory path at 1200-1800 UTC 23 Aug plotted in (a) and 1800 UTC 23-0800 UTC 24 Aug plotted in (b). The positions of Harvey at 1200 UTC 23 and 0800 UTC 24 Aug are indicated by the black "x." (c) Also shown are time series of mean air parcel pressure (hPa; dashed line) and water vapor mixing ratio ( $\mathrm{g} \mathrm{kg}^{-1}$; solid lines) for the subset of air parcels that originated below $850 \mathrm{hPa}$ in the Yucatan Peninsula at 1200 UTC 23 Aug 2017. Error bars represent the $90 \%$ confidence interval. CTL is shown in black, and DRY is shown in red.

the context of the brown ocean effect's influence on tropical cyclone maintenance inland, Andersen et al. (2013) defined inland tropical cyclones as systems at least $350 \mathrm{~km}$ from the nearest coastline. Harvey remained within $350 \mathrm{~km}$ of the coastline, with the eastern part of its circulation remaining over the Gulf of Mexico. Interestingly, the largest influence of soil conditions on intensity occurred prior to landfall while Harvey was still over the Gulf of Mexico. Harvey in the DRY and DRYC simulations reached a maximum intensity $\sim 10 \mathrm{~m} \mathrm{~s}^{-1}$ lower than the other simulations. The lower intensity in these simulations occurred because Harvey's development was temporarily interrupted as drier air that developed over the Yucatan Peninsula in conjunction with increased sensible heating over dry soils was entrained in Harvey's circulation. The drier air contributed to the development of an intense surfacebased cold pool beneath the vortex center that acted to stabilize the environment and temporarily reduce convection.

Last, the underlying soil moisture condition had a minimal influence on the rainfall as each simulation produced a record-breaking rainstorm. The location of the heaviest rains was linked to the track of Harvey and did vary among the simulations. A water budget analysis of each simulation indicated that the rainfall was primarily driven by vertically integrated water flux convergence. Brauer et al. (2020) also showed how supercells embedded in the principal rainband structures east of Harvey had high precipitation efficiency, thereby providing an additional factor in the extreme rainfall accumulations. Surface evapotranspiration, while varying among the simulations, contributed to less than $10 \%$ of the total available water and was not correlated to the amount of rain that occurred. This result differed from previous work that suggested evaporation of surface precipitation was important (although secondary) for hurricane rainfall (e.g., Trenberth et al. 2007). Possible reasons include the closeness of Harvey to the Gulf of Mexico as discussed above in the context of the brown ocean effect, and that the rains were forced by persistent lift of moist tropical air (that originated over Gulf of Mexico) by a frontogenetical coastal front.

The soil moisture perturbation experiment presented herein highlights how the underlying soil moisture can influence the evolution and hazards associated with a landfalling tropical system. While Harvey represents one case that included interaction with a midlatitude weather system (coastal front), a more expanded research effort to quantify the influence of soil moisture on landfalling tropical systems over numerous cases would provide a more complete picture of the statistically significant behavior. Future work on the influence of soil moisture on track, intensity, and rainfall should also utilize adjoint sensitivity analysis (e.g., Doyle et al. 2019), ensemble sensitivity analysis (e.g., Ancell and Hakim 2007), and ensemble synoptic analysis (e.g., Hakim and Torn 2008) given the recently documented disadvantages of using a simple set of WRF-ARW perturbation experiments (Ancell et al. 2018). A key aspect 
TABLE 3. Accumulated vertically integrated water tendencies (mm) from Eq. (4) for 69-106 $\mathrm{h} ; \Delta W$ represents the actual accumulated water tendency from the model, and the residual term represents $\Delta W$ minus the predicted accumulated water tendency from the righthand side of Eq. (4). All other symbols are defined in the text.

\begin{tabular}{lcccccc}
\hline \hline Simulation & $\Delta W(\mathrm{~mm})$ & $\frac{1}{g} \int_{p_{1}}^{p_{2}} \nabla \cdot\left(q_{T} V\right) d p(\mathrm{~mm})$ & $E_{v}(\mathrm{~mm})$ & $P(\mathrm{~mm})$ & Predicted (mm) & Residual $(\mathrm{mm})$ \\
\hline CTL & -4.0 & 63.0 & 48.4 & 6.9 & 78.2 & -8.3 \\
DRY & -3.4 & 55.4 & 3.5 & 56.2 & -4.3 & 4.3 \\
SAT & -4.1 & 63.9 & 8.8 & 71.3 & -7.0 & 0.9 \\
CTLC & -4.1 & 56.2 & 6.4 & 77.7 & -7.4 & 3.9 \\
DRYC & 1.8 & 50.3 & 10.5 & 65.1 & -3.4 & 5.2 \\
SATC & -1.8 & & & & -4.6 & 2.8 \\
\hline
\end{tabular}

of the future analyses of soil moisture influences on tropical systems will be comparison of tropical systems embedded in environments with weak versus strong interaction with midlatitude circulation features and processes. It is possible that the absence of midlatitude influences may allow the underlying soil moisture to play a larger role in track, rainfall, and intensity of tropical systems. Clearly, accurate depiction of soil moisture is an important component for accurate numerical weather prediction forecasts of tropical cyclones.

Acknowledgments. Support for this research was provided by NASA Grants 80NSSC18K1021 (principal investigator: Galarneau) and NNX16AN37G (principal investigator: Zeng). Susan Stillman assisted with the generation of Figs. 1b and 1c. This study benefitted from comments provided by three anonymous reviewers. All figures and calculations were generated using NCAR Command Language (NCL), version 6.3.0 (https://www.ncl.ucar.edu/); General Meteorology Package (GEMPAK), version 6.10 (https://www.unidata.ucar.edu/ software/gempak/); and Read/Interpolate/Plot (RIP), version 4.7 (https://www2. mmm.ucar.edu/wrf/users/docs/ripug.htm). Greg Thompson and the NCAR/Research Applications Laboratory are thanked for providing the base map with plotted station data in supplemental Fig. S1.

\section{REFERENCES}

Ancell, B., and G. J. Hakim, 2007: Comparing adjoint- and ensemble-sensitivity analysis with applications to observation targeting. Mon. Wea. Rev., 135, 4117-4134, https://doi.org/ 10.1175/2007MWR1904.1.

— A. Bogusz, M. J. Lauridsen, and C. J. Nauert, 2018: Seeding chaos: The dire consequences of numerical noise in NWP perturbation experiments. Bull. Amer. Meteor. Soc., 99, 615628, https://doi.org/10.1175/BAMS-D-17-0129.1.

Andersen, T., and M. Shepherd, 2017: Inland tropical cyclones and the "brown ocean" concept. Hurricanes and Climate Change, J. M. Collins and K. Walsh, Eds., Springer, 117-134.

_ D. E. Radcliffe, and J. M. Shepherd, 2013: Quantifying surface energy fluxes in the vicinity of inland-tracking tropical cyclones. J. Appl. Meteor. Climatol., 52, 2797-2808, https:// doi.org/10.1175/JAMC-D-13-035.1.
Atallah, E. H., and L. F. Bosart, 2003: The extratropical transition and precipitation distribution of Hurricane Floyd (1999). Mon. Wea. Rev., 131, 1063-1081, https://doi.org/10.1175/15200493(2003)131<1063:TETAPD > 2.0.CO;2.

Blake, E. S., and D. A. Zelinsky, 2018: National Hurricane Center tropical cyclone report: Hurricane Harvey (17 August-1 September 2017). NOAA/NWS Rep. AL092017, 77 pp., https://www.nhc.noaa.gov/data/tcr/AL092017_Harvey.pdf.

Bluestein, H. B., 1992: Synoptic-Dynamic Meteorology in Midlatitudes. Vol. I, Principles of Kinematics and Dynamics, Oxford University Press, 431 pp.

Bosart, L. F., 1984: The Texas coastal rainstorm of 17-21 September 1979: An example of synoptic-mesoscale interaction. Mon. Wea. Rev., 112, 1108-1133, https://doi.org/10.1175/1520-0493(1984) 112<1108:TTCROS $>2.0$. CO;2.

Brauer, N. S., J. B. Basara, C. R. Homeyer, G. M. McFarquhar, and P. E. Kirstetter, 2020: Quantifying precipitation efficiency and drivers of excessive precipitation in post-landfall Hurricane Harvey. J. Hydrometeor., 21, 433-452, https://doi.org/10.1175/ JHM-D-19-0192.1.

Brennan, M. J., 2011: National Hurricane Center tropical cyclone report: Tropical Storm Don (27-30 July 2011). NOAA/NWS Rep. AL042011, 15 pp., https://www.nhc.noaa.gov/data/tcr/ AL042011_Don.pdf.

Davis, C. A., and Coauthors, 2008: Prediction of landfalling hurricanes with the advanced hurricane WRF Model. Mon. Wea. Rev., 136, 1990-2005, https://doi.org/10.1175/2007MWR2085.1.

Doswell, C. A., III, H. E. Brooks, and R. A. Maddox, 1996: Flash flood forecasting: An ingredients-based methodology. Wea. Forecasting, 11, 560-581, https://doi.org/10.1175/1520-0434(1996) $011<0560$ :FFFAIB $>2.0 . \mathrm{CO} ; 2$.

Doyle, J. D., C. A. Reynolds, and C. Amerault, 2019: Adjoint sensitivity analysis of high-impact extratropical cyclones. Mon. Wea. Rev., 147, 4511-4532, https://doi.org/10.1175/MWR-D-19-0055.1.

Emanuel, K., J. Callaghan, and P. Otto, 2008: A hypothesis for the redevelopment of warm core cyclones over northern Australia. Mon. Wea. Rev., 136, 3863-3872, https://doi.org/10.1175/2008MWR2409.1.

Evans, C., R. S. Schumacher, and T. J. Galarneau Jr., 2011: Sensitivity in the overland reintensification of Tropical Cyclone Erin (2007) to near-surface soil moisture characteristics. Mon. Wea. Rev., 139, 3848-3870, https://doi.org/10.1175/2011MWR3593.1.

Fernández-Cabán, P. L., and Coauthors, 2019: Observing Hurricane Harvey's eyewall at landfall. Bull. Amer. Meteor. Soc., 100, 759775, https://doi.org/10.1175/BAMS-D-17-0237.1.

Galarneau, T. J., Jr., and C. A. Davis, 2013: Diagnosing forecast errors in tropical cyclone motion. Mon. Wea. Rev., 141, 405430, https://doi.org/10.1175/MWR-D-12-00071.1.

- and T. M. Hamill, 2015: Diagnosis of track forecast errors for Tropical Cyclone Rita (2005) using GEFS reforecasts. Wea. 
Forecasting, 30, 1334-1354, https://doi.org/10.1175/WAF-D15-0036.1.

Gall, R., F. Toepfer, F. Marks, and E. Rappaport, 2014: Hurricane forecast improvement project years five to ten strategic plan. NOAA/Hurricane Forecast Improvement Project Tech. Rep. HFIP2014-1.1a, 52 pp., http://www.hfip.org/documents/ HFIP_StrategicPlan_Yrs5-10_Nov05_2014_Update.pdf.

Hakim, G. J., and R. D. Torn, 2008: Ensemble synoptic analysis. Synoptic-Dynamic Meteorology and Weather Analysis and Forecasting: A Tribute to Fred Sanders, Meteor. Monogr., No. 55, Amer. Meteor. Soc., https://doi.org/10.1175/0065-9401-33.55.147.

Hao, W., and L. F. Bosart, 1987: A moisture budget analysis of the protracted heat wave in the southern plains during the summer of 1980. Wea. Forecasting, 2, 269-288, https://doi.org/10.1175/ 1520-0434(1987)002<0269:AMBAOT>2.0.CO;2.

Higgins, R. W., W. Shi, E. Yarosh, and R. Joyce, 2000: Improved United States precipitation quality control system and analysis. NCEP/Climate Prediction Center Atlas 7, NOAA, accessed 3 March 2019, http://www.cpc.ncep.noaa.gov/research_papers/ ncep_cpc_atlas/7/toc.html.

Houze, R. A., 2010: Clouds in tropical cyclones. Mon. Wea. Rev., 138, 293-344, https://doi.org/10.1175/2009MWR2989.1.

Jones, T., P. Skinner, N. Yussouf, K. Knopfmeier, A. Reinhart, and D. Dowell, 2019: Forecasting high-impact weather in landfalling tropical cyclones using a Warn-on-Forecast system. Bull. Amer. Meteor. Soc., 100, 1405-1417, https://doi.org/ 10.1175/BAMS-D-18-0203.1.

Keyser, D., M. J. Reeder, and R. J. Reed, 1988: A generalization of Petterssen's frontogenesis function and its relation to the forcing for vertical motion. Mon. Wea. Rev., 116, 762-781, https://doi.org/ 10.1175/1520-0493(1988)116<0762:AGOPFF>2.0.CO;2.

Kilroy, G., R. K. Smith, M. T. Montgomery, B. Lynch, and C. EarlSpurr, 2016: A case-study of a monsoon low that formed over the sea and intensified over land as seen in ECMWF analyses. Quart. J. Roy. Meteor. Soc., 142, 2244-2255, https://doi.org/10.1002/qj.2814.

Klotzbach, P. J., S. G. Bowen, R. Pielke Jr., and M. Bell, 2018a: Continental U.S. hurricane landfall frequency and associated damage: Observations and future risks. Bull. Amer. Meteor. Soc., 99, 1359-1376, https://doi.org/10.1175/BAMS-D-17-0184.1.

, C. J. Schreck III, J. M. Collins, M. M. Bell, E. S. Blake, and D. Roache, 2018b: The extremely active 2017 North Atlantic hurricane season. Mon. Wea. Rev., 146, 3425-3443, https:// doi.org/10.1175/MWR-D-18-0078.1.

Kossin, J. P., 2018: A global slowdown of tropical-cyclone translation speed. Nature, 558, 104-107, https://doi.org/10.1038/ s41586-018-0158-3.

Lakshmanan, V., T. Smith, G. Stumpf, and K. Hondl, 2007: The Warning Decision Support System-Integrated Information. Wea. Forecasting, 22, 596-612, https://doi.org/10.1175/WAF1009.1.

Landsea, C. W., and J. L. Franklin, 2013: Atlantic hurricane database uncertainty and presentation of a new database format. Mon. Wea. Rev., 141, 3576-3592, https://doi.org/10.1175/MWR-D-12-00254.1.

Lin, Y., 2011: GCIP/EOP surface: Precipitation NCEP/EMC 4KM Gridded Data (GRIB) Stage IV data, version 1.0. UCAR/NCAREarth Observing Laboratory, accessed 22 December 2017, https://doi.org/10.5065/D6PG1QDD.

Liu, L., J. Xu, Y. Wang, and Y. Duan, 2019: Contribution of recycling of surface precipitation to landfalling tropical cyclone rainfall: A modeling study for Typhoon Utor (2013). J. Geophys. Res. Atmos., 124, 870-885, https://doi.org/ 10.1029/2018JD029380.

Maddox, R. A., C. F. Chappell, and L. R. Hoxit, 1979: Synoptic and meso- $\alpha$ scale aspects of flash flood events. Bull. Amer. Meteor. Soc., 60, 115-123, https://doi.org/10.1175/1520-0477-60.2.115.

Reichle, R., G. De Lannoy, R. D. Koster, W. T. Crow, J. S. Kimball, and Q. Liu, 2018: SMAP L4 global 3-hourly 9 km EASE-Grid surface and root zone soil moisture analysis update, version 4. NASA National Snow and Ice Data Center Distributed Active Archive Center, accessed 17 September 2017, https:// doi.org/10.5067/60HB8VIP2T8W.

Saha, S., and Coauthors, 2010: The NCEP Climate Forecast System Reanalysis. Bull. Amer. Meteor. Soc., 91, 1015-1058, https:// doi.org/10.1175/2010BAMS3001.1.

_ , and Coauthors, 2014: The NCEP Climate Forecast System version 2. J. Climate, 27, 2185-2208, https://doi.org/10.1175/ JCLI-D-12-00823.1.

Schumacher, R. S., and C. A. Davis, 2010: Ensemble-based forecast uncertainty analysis of diverse heavy rainfall events. Wea. Forecasting, 25, 1103-1122, https://doi.org/10.1175/2010WAF2222378.1.

Seager, R., L. Goddard, J. Nakamura, N. Henderson, and D. E. Lee, 2014: Dynamical causes of the 2010/11 Texas-northern Mexico drought. J. Hydrometeor., 15, 39-68, https://doi.org/ 10.1175/JHM-D-13-024.1.

Simpson, R. H., and H. Saffir, 1974: The hurricane disasterpotential scale. Weatherwise, 27, 169-186, https://doi.org/10.1080/ 00431672.1974 .9931702$.

Skamarock, W. C., and Coauthors, 2008: A description of the Advanced Research WRF version 3. NCAR Tech. Note NCAR/TN-475+STR, 113 pp., https://doi.org/10.5065/ D68S4MVH.

Smith, T. M., and Coauthors, 2016: Multi-Radar Multi-Sensor (MRMS) severe weather and aviation products: Initial operating capabilities. Bull. Amer. Meteor. Soc., 97, 1617-1630, https://doi.org/10.1175/BAMS-D-14-00173.1.

Torn, R. D., T. J. Elless, P. P. Papin, and C. A. Davis, 2018: Tropical cyclone track sensitivity in deformation steering flow. Mon. Wea. Rev., 146, 3183-3201, https://doi.org/10.1175/MWR-D-18-0153.1.

Trenberth, K. E., C. A. Davis, and J. Fasullo, 2007: Water and energy budgets of hurricanes: Case studies of Ivan and Katrina. J. Geophys. Res., 112, D23106, https://doi.org/10.1029/2006JD008303.

Trier, S. B., C. A. Davis, and D. A. Ahijevych, 2010: Environmental controls on the simulated diurnal cycle of warm-season precipitation in the continental United States. J. Atmos. Sci., 67, 1066-1090, https://doi.org/10.1175/2009JAS3247.1.

Wei, N., and Y. Li, 2013: A modeling study of land surface process impacts on inland behavior of Typhoon Rananim (2004). $A d v$. Atmos. Sci., 30, 367-381, https://doi.org/10.1007/s00376-012-1242-5.

Wurman, J., and K. Kosiba, 2018: The role of small-scale vortices in enhancing surface winds and damage in Hurricane Harvey (2017). Mon. Wea. Rev., 146, 713-722, https://doi.org/10.1175/ MWR-D-17-0327.1.

Zhang, J. A., R. F. Rogers, and V. Tallapragada, 2017: Impact of parameterized boundary layer structure on tropical cyclone rapid intensification forecasts in HWRF. Mon. Wea. Rev., 145, 1413-1426, https://doi.org/10.1175/MWR-D-16-0129.1. 